
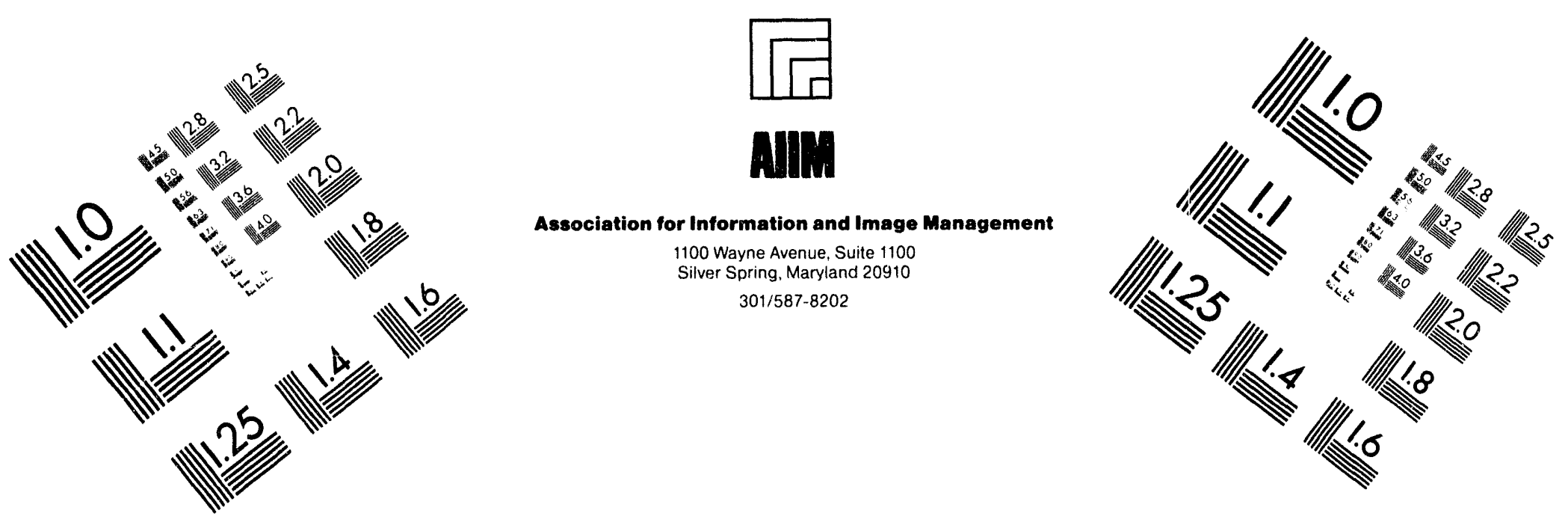

Centimeter

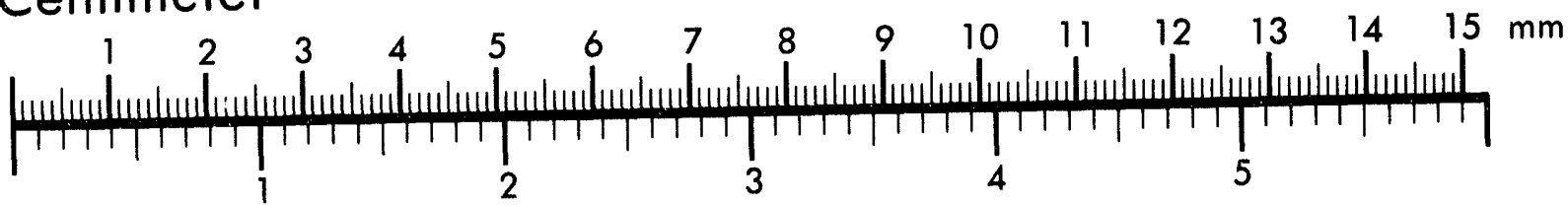
Inches
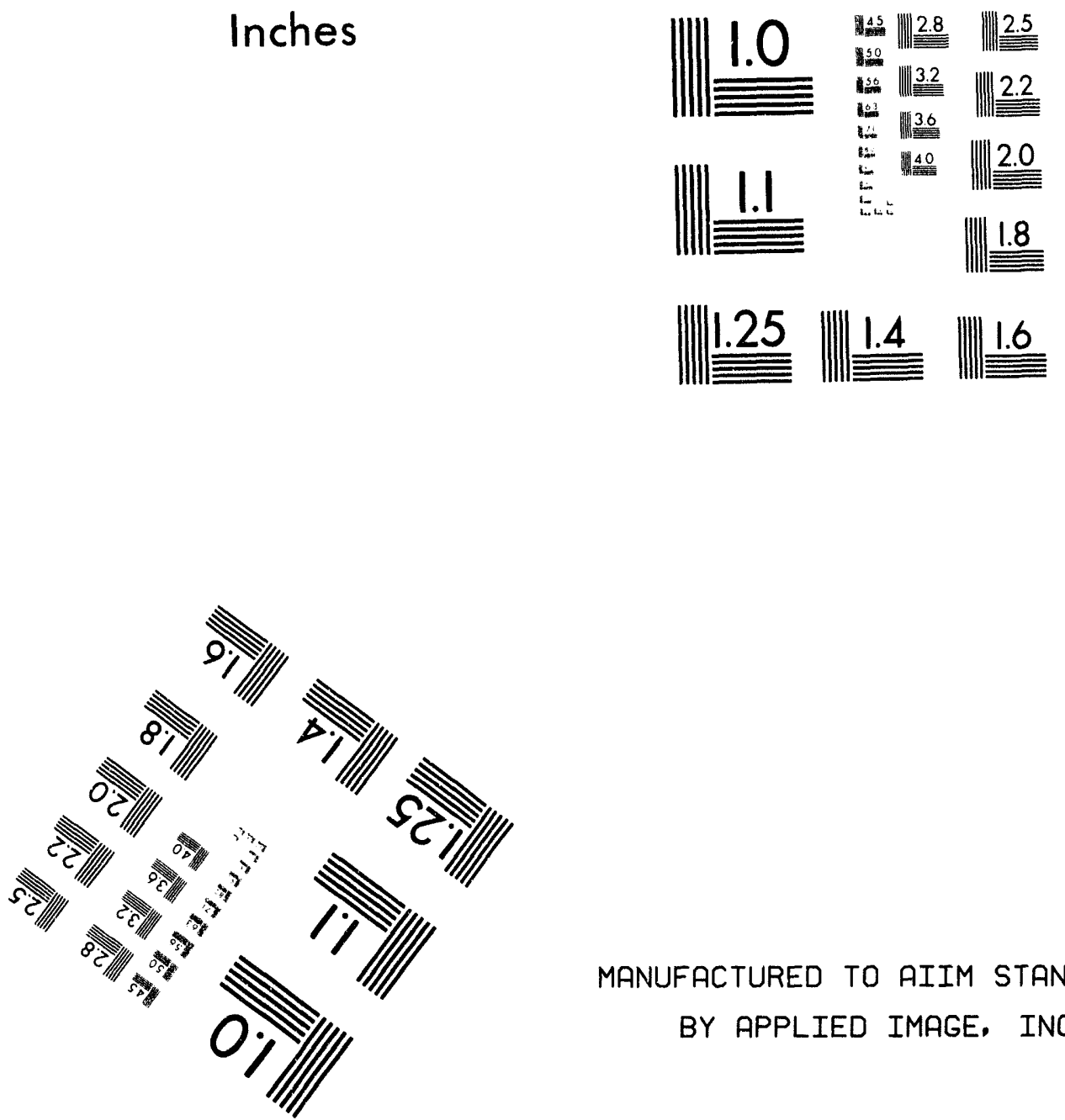

MANUFACTURED TO AIIM STANDARDS

BY APPLIED IMAGE, INC.

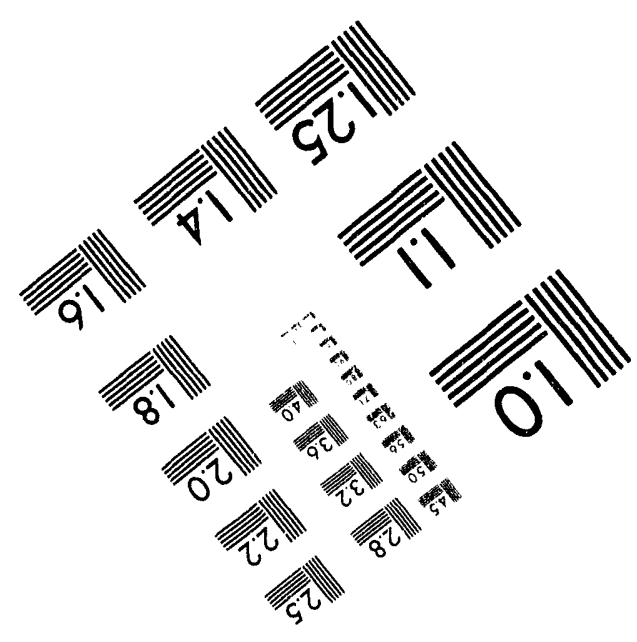



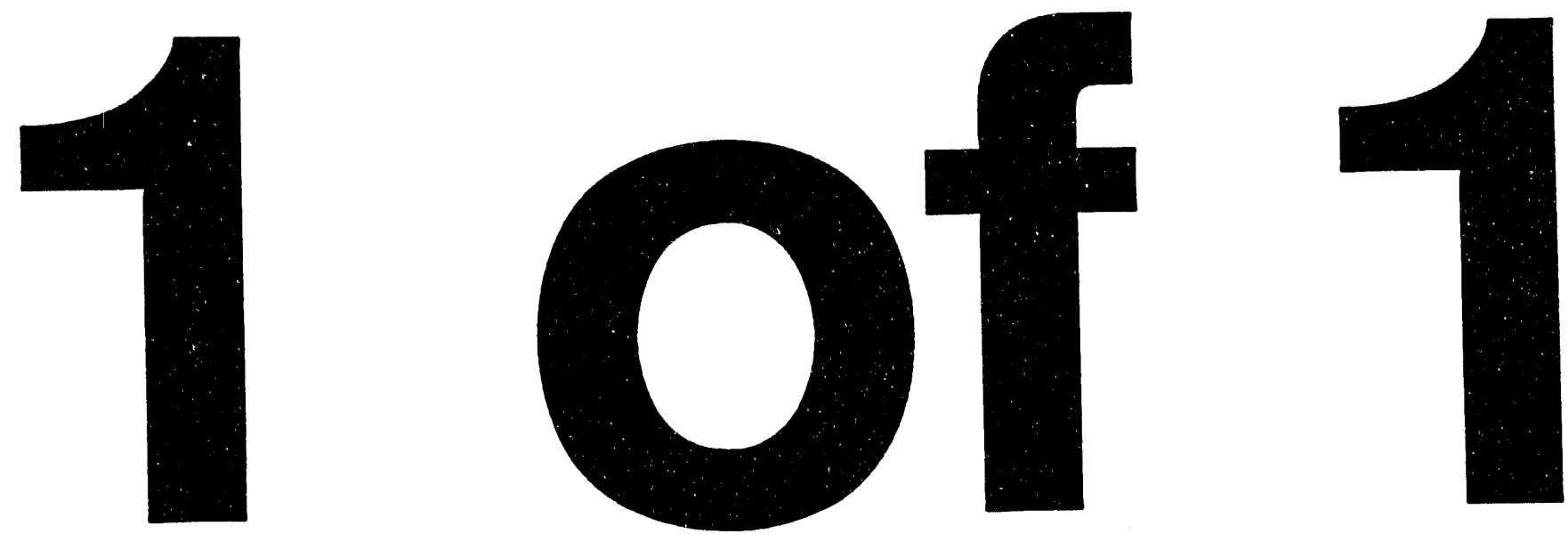
PNL-SA-24235

\section{TRITIUM/HYDROGEN BARRIER DEVELOPMENT}
G. W. Hollenberg
E. P. Simonen
A. Terlain ${ }^{(a)}$
G. Kalinin ${ }^{(\mathfrak{b})}$

June 1994

Presented at the

Third International Symposium

on Fusion Nuclear Technology

June 27 - July 1, 1994

Los Angeles, California

Prepared for

the U.S. Department of Energy

under Contract DE-AC06-76RLO 1830

Pacific Northwest Laboratory

Richland, Washington 99352

(a) CEA, France

(b) ITER Team, Germany

This report was prepared as an account of work sponsored by an agency of the United States Government. Neither the United States Government nor any agency thereof, nor any of their employees, makes any warranty, express or implied, or assumes any legal liability or responsibility for the accuracy, completeness, or usefulness of any information, apparatus, product, or process disclosed, or represents that its use would not infringe privately owned rights. Reference herein to any specific commercial product, process, or service by trade name, trademark, manufacturer, or otherwise does not necessarily constitute or imply its endorsement, recommendation, or favoring by the United States Government or any agency thereof. The views and opinions of authors expressed herein do not necessarily state or reflect those of the United States Government or any agency thereof. 
Tritium/Hydrogen Barrier Development

G. W. Hollenberg and E. P. Simonen

Pacific Northwest Laboratory ${ }^{(a)}$

Richland, Washington 99352 U.S.A.

G. Kalinen

ITER Team, Germany

A. Terlain

CEA, France

\begin{abstract}
A review of hydrogen permeation barriers that can be applied to structural metals used in fusion power plants is presented. Both implanted and chemically available hydrogen isotopes must be controlled in fusion plants. The need for permeation barriers appears strongest in Li17-Pb blanket designs, although barriers also appear necessary for other blanket and coolant systems. Barriers that provide greater than a 1000 fold reduction in the permeation of structural metals are desired. In laboratory experiments, aluminide and titanium ceramic coatings provide permeation reduction factors, PRFs, from 1000 to over 100,000 with a wide range of scatter. The rate-controlling mechanism for hydrogen permeation through these barriers may be related to the number and type of defects in the barriers. Although these barriers appear robust and resistant to liquid metal corrosion, irradiation tests which simulate blanket environments result in very low PRFs in comparison to laboratory experiments, i.e., $<150$. It is anticipated from fundamental research activities that the REID enhancement of hydrogen diffusion in oxides may contribute to the lower permeation reduction factors during in-reactor experiments.
\end{abstract}

(a) Pacific Northwest Laboratory is operated for the U.S. Department of Energy by Battelle Memorial Institute under Contract DE-AC06-76RLO 1830. 


\title{
Tritium/Hydrogen Barrier Development
}

\author{
G. W. Hollenberg, E. P. Simonen, A. Terlain, and G. Kalinin
}

Introduction

In D-T fusion plants, the management of all hydrogen isotopes is implicit; assuming that coolant temperatures will be near $300^{\circ} \mathrm{C}$ and that no major relaxation in tritium effluent limits occurs.

Regardless of the design and configuration of these plants, it is anticipated that hydrogen barriers will be an integral part of the tritium management system. Hydrogen barriers are necessary to kinetically limit the achievement of thermodynamic or isotopic equilibrium through hermetic boundaries.

Uncontrolled tritium or hydrogen transport in fusion plants can lead to tritium inventory buildup in the plant, tritium contaminated effluents, high tritium concentrations in work areas, hydrogen embrittlement of metals, and more difficult tritium processing. Only hydrogen degradation of the mechanical properties of structural alloys is an issue which can be hampered by effective barriers.

Tritium/hydrogen barriers have evolved in a variety of applications during the past several decades. In addition to reducing the permeation reduction factors when applied to structural materials, tritium barriers must also survive the same conditions as the base metal, i.e., corrosion, irradiation, mechanical stresses, etc. To permeate a barrier-coated metal, a hydrogen isotope must be adsorbed on the surface, diffuse through the barrier, be incorporated into the base metal, diffuse through the base metal and undergo desorption at the opposite surface. Simple surface oxides have provided about one order of magnitude reduction in hydrogen permeation for many structural materials. Simple oxidation of metals is not considered within this paper although it may be effective for certain regions of the plant. Coatings or layers which are primarily meant for other functions, i.e., beryllium as a plasma facing component, are also not discussed even though they may retard hydrogen isotopic transport. For applications requiring high fluence tolerance, structural metals are already challenged without the 
added constraint of producing tritium impermeable oxides. This paper considers the composite concept of a viable structural material covered with a thin nonstructural barrier. Varying success has been achieved with heterogeneous carbide, nitride and oxide coatings applied to metals as shown in Table I. Far greater success has been reported for intermetallic coatings, such as aluminides and titanium ceramic coatings, which generate high permeation reduction factors (up to 10,000) and yet possess reasonable durability. The proposed rate limiting mechanisms, i.e., diffusional, recombination and microcrack area, for these effective hydrogen barriers are difficult to discriminate between because of data limitations and contrasting results. A variety of experimental and developmental activities on tritium barriers for hydrogen isotope permeation are underway, including in situ reactor testing of these barriers. This paper provides a review of the available literature on both developmental and experimental tritium/hydrogen barrier coatings, but focuses on the more detailed investigations of commercially-available aluminide and titanium-based coatings.

In Table I, a listing of some of the surface treatments considered by several investigators is included. In Figure 1, Tanabe ${ }^{19}$ has presented a basis for the logic in pursuing these approaches. Note that both of these elements, $\mathrm{Al}$ and $\mathrm{Ti}$, possess very high free energies of formation of the oxide. Many consider the oxide to be the actual barrier regardless of the forming technique. Hence, the stability of these oxides, $\mathrm{Al}_{2} \mathrm{O}_{3}$ and $\mathrm{TiO}_{2}$, and their ability to reform even in low oxygen partial pressure situation are major virtues in comparison to oxides such as $\mathrm{Cr}_{2} \mathrm{O}_{3}$ as pointed out by $\mathrm{Terai}^{14}$.

Although metals such as tungsten and gold possess permeabilities low enough to permit them to be considered as hydrogen permeation barriers, most of the work to date has been focused upon ceramic based barriers. In Figure 2, the relative permeabilities of two types of silicon carbide ${ }^{20-21}$ and alumina $^{21}$ are compared to 316 stainless stecl. Ferritic steels, like MANET, are approximately one order of magnitude higher permeability than 316 stainless steel, probably as a result of the more open 


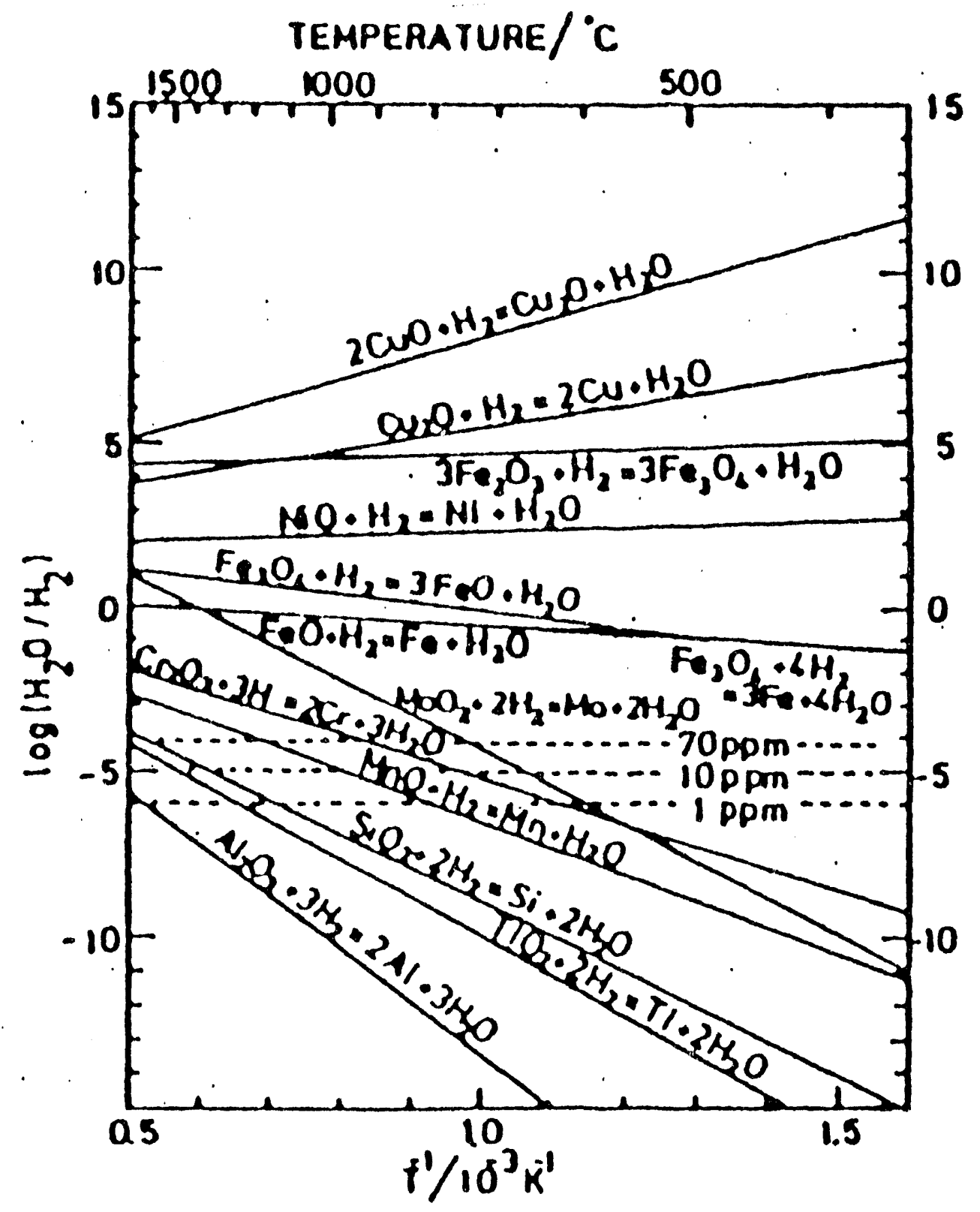

Figure 1. Comparison of Oxidation of a Metal by Water Vapor or Reduction of the Metal Oxide by Hydrogen at Various Water to Hydrogen Ratios by Tanabe et al. ${ }^{19}$. 


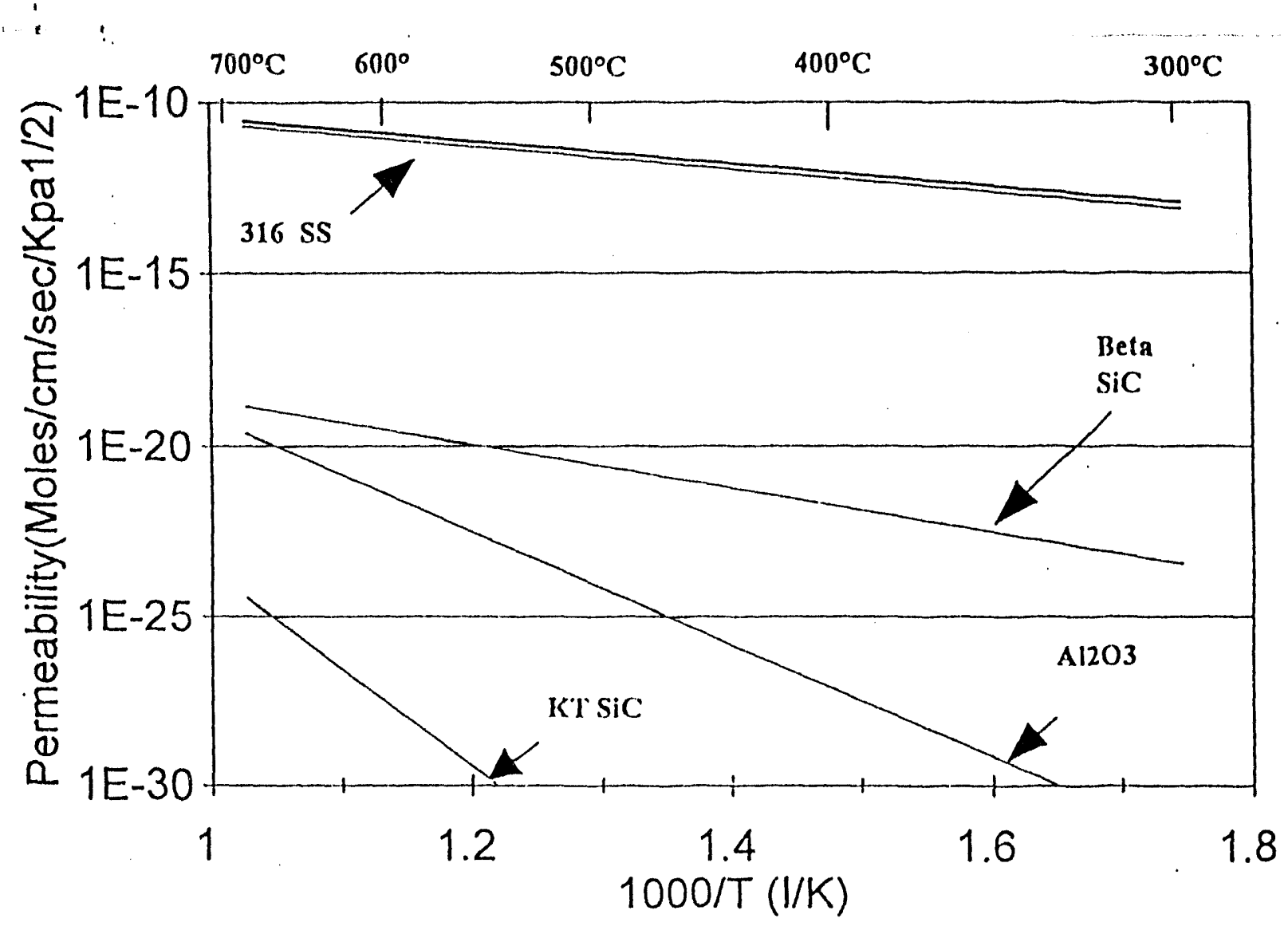

Figure 2. Comparison of the Permeabilities of $316 \mathrm{SS}$ With Those of $\mathrm{Al}_{2} \mathrm{O}_{3}$ and $\mathrm{SiC}$.

Table 1. Systems Considered as Tritium/Hydrogen Barriers

\begin{tabular}{|c|c|c|c|}
\hline Barrier Coating & Base Metals & Permeation Reduction & Source \\
\hline $\begin{array}{l}\text { Aluminide } \\
\text { (or } \mathrm{Al}_{2} \mathrm{O}_{3} \text { ) }\end{array}$ & $\begin{array}{l}\text { 316SS, MANET, } \\
\text { TZM, Hastelloy-X, Ni }\end{array}$ & 10 to $>10,000$ & $\begin{array}{l}\text { McGuire', Forcey }{ }^{2,3} \\
\text { Van Deventer } \\
\text { Gilbert }^{5} \text {, Perujo } \\
\text { Sohki, } \\
\text { Thompson' }\end{array}$ \\
\hline $\mathrm{TiC}, \mathrm{TiN} \& \mathrm{TiO}_{2}$ & $\begin{array}{l}\text { 3i } 6 \mathrm{SS}, \\
\text { MANET, TZM, } \\
\text { Ti }\end{array}$ & $<10$ to $>10,000$ & $\begin{array}{l}\text { Shan }{ }^{10}, \text { Forcey }{ }^{11}, \\
\text { Bonelli }^{12}, \text { Nelson }^{13}\end{array}$ \\
\hline $\mathrm{Cr}\left(\right.$ or $\left.\mathrm{Cr}_{2} \mathrm{O}_{3}\right)$ & $316 \mathrm{SS}$ & 10 & Terai $^{14}$ \\
\hline $\mathrm{Si}$ & Steels & 10 & Swansiger ${ }^{15}$ \\
\hline $\mathrm{BN}$ & $304 S S$ & 100 & Matsuyama $^{16}$ \\
\hline $\mathrm{Sn}$ & Ferritic Steel & Rapidly Degraded & Bowker ${ }^{17}$ \\
\hline $\mathrm{H}_{3} \mathrm{PO}_{4}$ Glass & $304 S S$ & 100 (unstable) & McGuire' \\
\hline $\mathrm{N}$ & Iron & 10 to 20 & Brass $^{18}$ \\
\hline
\end{tabular}


structure of the face center cubic crystal structure. Hence, the importance of permeability barriers appears even more important for those alloys which demonstrate high irradiation resistance. The important feature of this graph is that the permeabilities of these ceramics are almost 10 orders of magnitude lower than the metal permeabilities. Consequently, a thin coating of these cerarnics $(<1 \mu \mathrm{m})$ could be considered feasible for reducing the permeability of a sheet of metal $(1000 \mu \mathrm{m})$ by a factor of a million. The review of available information on actual barriers provides a perspective which is far more complex than this simplistic view. Our discussion will be divided into a comparative review of results on the aluminizing process in which some of the more spectacular successes have occurred. As will be shown in the text that follows, the ability to reach these theoretical reductions in tritium or hydrogen permeability may be more a function of coating quality rather than these intrinsic permeabilities.

Sources of Hydrogen Isotopes in Fusion Reactors

In Figure 3 the two general categories of hydrogen isotope sources are shown as implantation and chemical sources. Chemical sources require the process of absorption followed by diffusion, while implantation sources essentially eliminate the process of absorption from hydrogen isotope permeation past the barrier. In considering the application of hydrogen permeation barriers it will be very important to consider the source of hydrogen isotopes which the barriers must act against.

1. For many years, plasma driven ion experiments have been the source of a number of excellent studies on non-barrier coated structural and plasma facing materials. The accelerated diffusion originating from these ions provided data which was both of scientific and engineering interest. Although there are a few high energy deuterium and tritium ions $(50 \mathrm{Kev})$, most of the plasma driven ions are at lower energies, 10 to $200 \mathrm{ev}$. The actual penetration depth of such ions is relatively low for the most part, $0.01 \mu \mathrm{m}$, as can be seen in Table I. Most of these ions are intentionally focused upon the divertor region at the bottom of the torus, such that the ion flux 
there can be more than three orders of magnitude higher than at the first wall ${ }^{24}$. Because of the low penetration distance of plasma driven hydrogen isotopes, their net effect on permeation is dominated by hydrogen isotope recycling back into the plasma.

2. A second type of implantation with far greater depth of penetration is from the tritium production in the blanket of a fusion plant. Tritium ions possess an initial energy of $2.7 \mathrm{Mev}$ which can propel them as far as $20 \mu \mathrm{m}^{23}$ into juxtapositioned structural materials. Tiie flux of these ions into the structural material is very design dependent since it depends upon the local geometry, lithium density, and lithium cross section which is highly dependent on the effects of neutron multiplication, neutron absorption, etc. Nevertheless, the depth of penetration is very important when considering thin barriers $(<50 \mu \mathrm{m})$ with the intent to reduce permeation by many orders of magnitude.

3. The internal generation of hydrogen through $(n, p)$ reactions with metallic atoms in structural materials is a source of protium which cannot be avoided when considering materials degradation. Note in Table Il that in the first wall region the hydrogen from the $(n, p)$ reactions exceeds the tritium/deuterium flux from the plasma driven $(D, T)$ implantations. If the same neutron flux exists at the divertor, the plasma driven ion flux then exceeds the hydrogen generated from $(n, p)$ reactions.

In Table III some of the chemical sources of tritium are listed with representative levels of effective partial pressures developed for certain designs. Note that the highest tritium partial pressures exist in the Li17- $\mathrm{Pb}$ blanket concept while the lowest partial pressure for all hydrogen isotopes would be in a pure lithium blanket concepts. The solid breeder concepts that have evolved recently possess a $5 \mathrm{~Pa}$ tritium partial pressure at the outlet but typically have 100 Pa hydrogen or deuterium in the sweep gas to accelerate tritium removal. The partial pressure of hydrogen in PWR water is purposefully high, primarily as a method to limit oxidation of metallic components. Water chemistry specifications are not available for fusion plants in such detail but trade-offs must be made between hydrogen injection 


\section{Hydrogen/Tritium Source Terms for Fusion Reactor Permeation}

\section{Implantation Source}

- Plasma lons
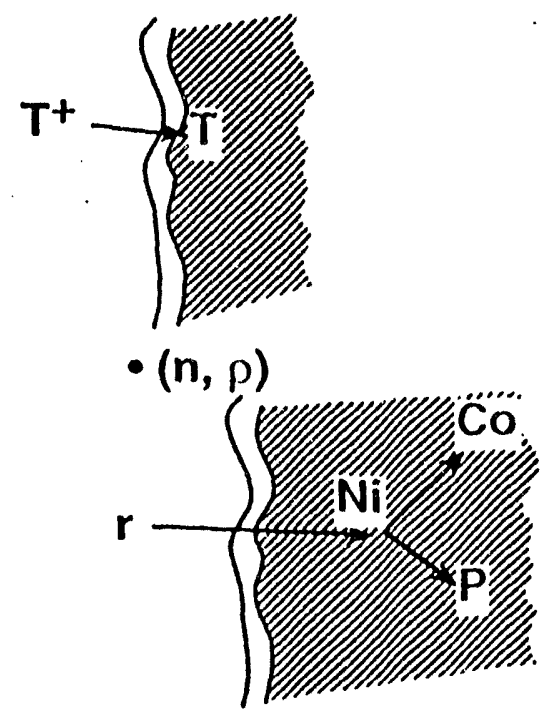

- Breeding Blanket

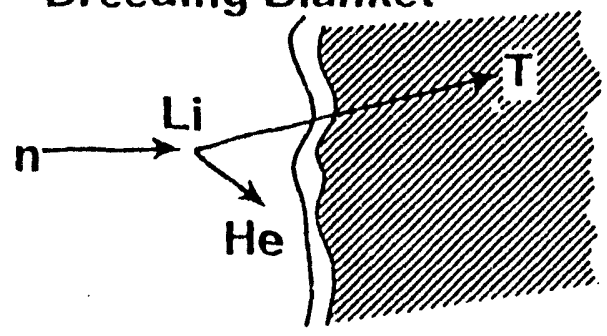

Chemical Sources

- Partial Pressure

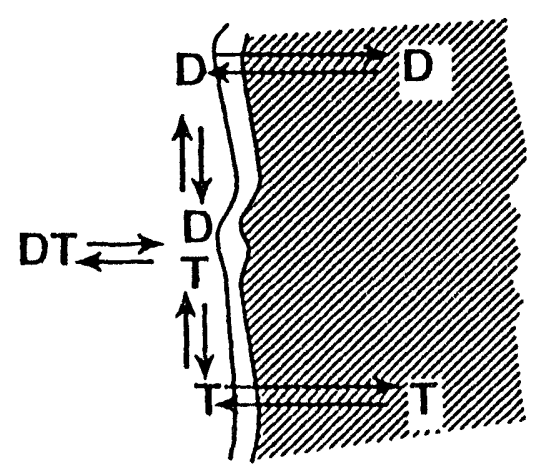

- Isotopic Exchange

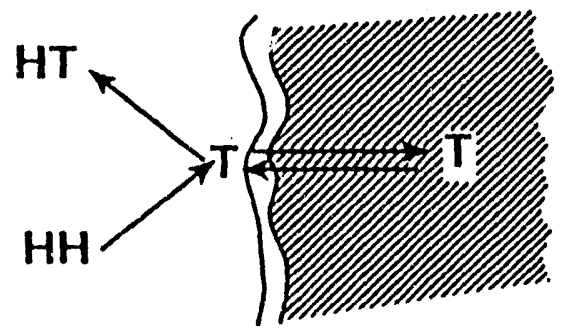

Figure 3. Tritium/Hydrogen Sources in Fusion Reactors are Separated into Implantation and Chemical Sources 
Table II. Hydrogen Implantation Isotope Sources in Fusion Reactors

First Wall

Divertor

\begin{tabular}{lc|ccc|cc}
\hline \hline & $\begin{array}{c}\text { Hydrogen } \\
\text { Isotope }\end{array}$ & Energy & $\begin{array}{c}\text { Recoil } \\
\text { Range }\end{array}$ & $\begin{array}{c}\text { Flux } \\
\text { ions } / \mathrm{cm}^{2} / \mathrm{s}\end{array}$ & $\begin{array}{c}\text { Flux } \\
\text { Energy }\end{array}$ & \begin{tabular}{c} 
ions $/ \mathrm{cm}^{2} / \mathrm{s}$ \\
\hline Plasma Driven $^{25}$
\end{tabular} \\
D\&T & $55 \mathrm{ev}$ & $<0.01 \mu \mathrm{m}$ & $1 \times 10^{16}$ & $130 \mathrm{ev}$ & $4000 \times 10^{16}$ \\
$(\mathrm{n}, \mathrm{p})^{29}$ & $\mathrm{H}$ & $\mathrm{n} / \mathrm{a}$ & $\mathrm{n} / \mathrm{a}$ & $150 \times 10^{16}$ & $\mathrm{n} / \mathrm{a}$ & $<150 \times 10^{16}$ \\
Breeding Blanket & $\mathrm{T}$ & $2.7 \mathrm{Mev}$ & $20 \mu \mathrm{m}$ & $\begin{array}{c}\text { Design } \\
\text { dependent }\end{array}$ & $\mathrm{n} / \mathrm{a}$ & $\mathrm{n} / \mathrm{a}$ \\
\hline \hline
\end{tabular}

Fluxes based upon ITER neutron wall loadings of a $1 \mathrm{~mm}$ thick component considering integrated transport ${ }^{26}$.

Table III. Tritium Chemical Sources in Fusion Reactors

\begin{tabular}{|c|c|c|}
\hline Component & Isotope & Partial Pressure \\
\hline Within First Wall ${ }^{25}$ & $T \& D$ & 1 to $10 \mathrm{~Pa}^{4}$ \\
\hline $\begin{array}{l}\text { Blanket Options } \\
\qquad \begin{array}{l}\text { Li17- }-\mathrm{Pb}^{28} \\
\mathrm{Li}^{29} \\
\text { Solid Breeder } \\
\text { Flibe }\end{array}\end{array}$ & $\begin{array}{l}T \\
T \\
T \\
\text { H or D } \\
T\end{array}$ & $\begin{array}{c}30 \text { to } 1000 \mathrm{~Pa}^{5} \\
9 \times 10^{-4} \mathrm{~Pa} \\
5 \mathrm{~Pa} \\
100 \mathrm{~Pa} \\
10 \mathrm{~Pa}\end{array}$ \\
\hline PWR Coolant Water $\left(332^{\circ} \mathrm{C}\right)^{31}$ & $\mathrm{H}$ & $<15000 \mathrm{~Pa}$ \\
\hline
\end{tabular}

and hydrazine additions and allowable corrosion. Radiolysis of water may provide the lower bound for protium pressure in fusion facilities. Clearly, the chemical sinks for hydrogen isotopes in a fusion system depend upon the exact design makeup. Generally, the plasma chamber, coolants, and lithium metal, in the liquid lithium concept, form strong sinks. Isotopic exchange can be seen as the obvious driving force in most cases with contamination of the coolant water by tritium and contamination of the plasma and blanket by protium being the issue addressed by permeation. 


\section{Design Criteria}

In considering the permeation criteria for the implanted ions, there have been several design issues resulting in suggested permeation reductions by barriers from 100 to 10,000 , depending on the design specifics. In general, it can be said that improved tritium barrier performance typically reduces the need for more expensive and complex processing alternatives within the fusion facility. First, recycling of tritium and deuterium ions lost from the plasma has been a focus of several engineering studies based upon simple fueling economics of these valuable isotopes. Barriers appear not to present distinct advantages in recycling by themselves. Secondly, tritium losses from the fusion facility must be considered as effluent in the environment which must be minimized either by permeation reduction or expensive isotopic separation. For example in NET, a goal of 10,000 Ci/day of tritium permeation was adopted as a balance between these options ${ }^{32}$. Malara concluded that a factor of 100 reduction in the permeability of $316 \mathrm{SS}$ provides for more compact and less expensive extraction equipment for an Li17-Pb blanket. Even greater reductions would be necessary for a martensitic alloy. In the HiLife design work, Longhurst ${ }^{30}$ calculated that it was necessary for barriers to reduce permeation by 10,000 in order to satisfy their design goals. Sze ${ }^{29}$ indicated that barriers with between 100 and 1000 reduction in permeability were required for stainless steel designs when considering blankets including

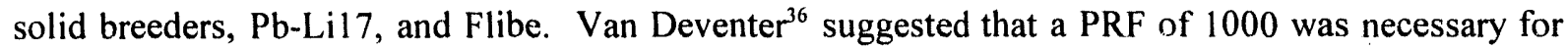
austenitic stainless steels as first wall materials.

Reite ${ }^{28}$ has provided the most detailed evaluation of barriers impact on tritium permeation in an Li17-Pb blanket for DEMO with and without a TiC barrier coating to MANET structural components. In Figure 4, the calculated tritium permeation into the coolant for theoretical conditions of no coating, a coating on the Li17-PB side only, and for coatings on all surfaces in the DEMO Li17-Pb blanket with a MANET structure are shown. Note that the application of the coating to both inner and outer surfaces leads to 5 orders of magnitude reduction in the tritium permeation into the coolant. 
The thermodynamic equilibrium partial pressure of hydrngen, i.e., without electrolysis in an irradiation environment, is shown in Table III from Radford" for LWR water chemistry. It should be anticipated that hydrogen from steam generators will be a part of fusion power systems until another technology replaces it. As such, back streaming of hydrogen into the blanket region of the fusion plant from the steam generator remains an issue which requires permeation barriers, albeit without the concerns of irradiation stability. In plant designs containing materials with strong hydrogen affinity, i.e., lithium metal, titanium, etc., barrier materials may be as important for keeping hydrogen out of the reactor as keeping tritium in.

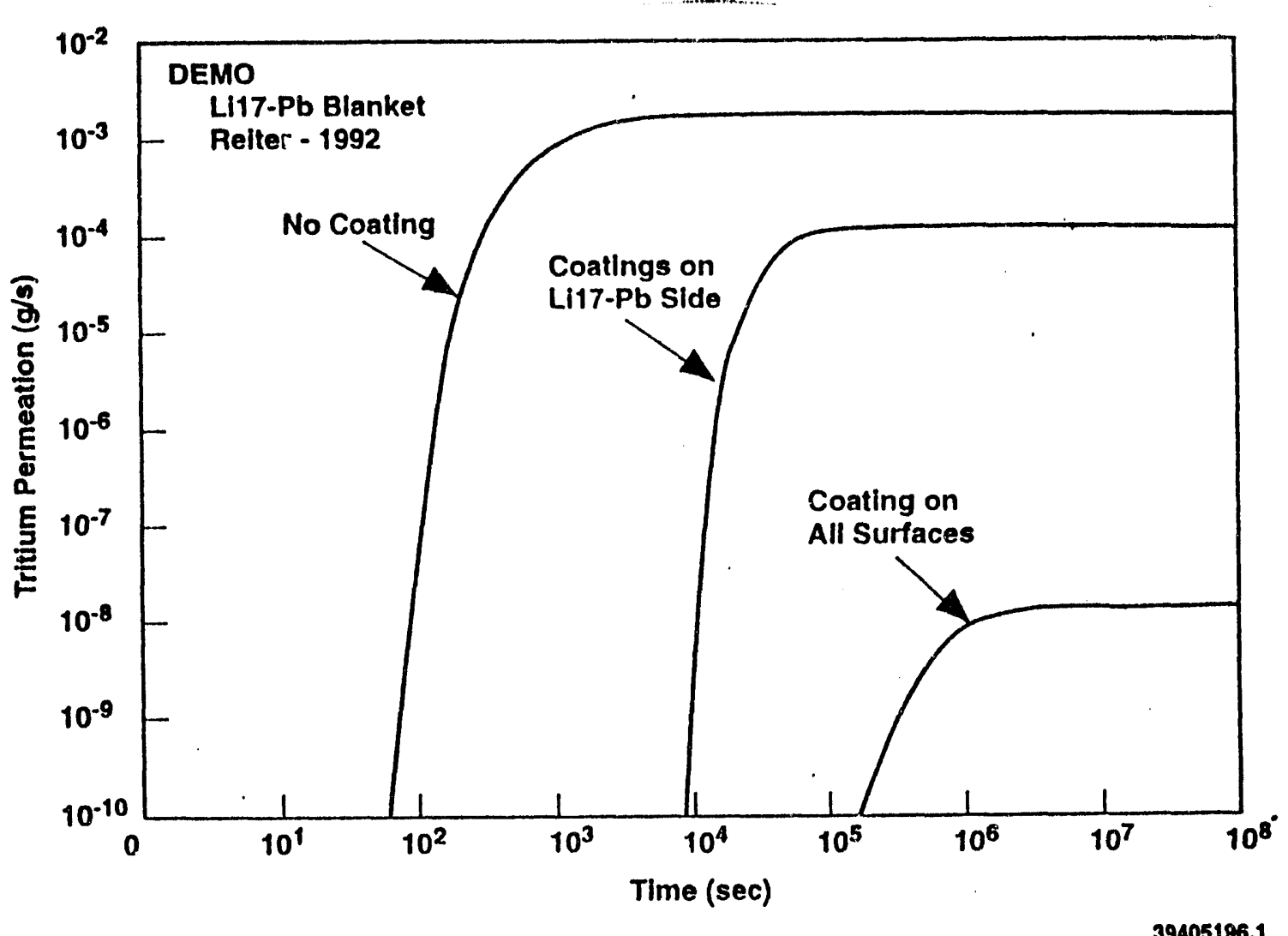

Figure 4. Calculated Tritium Permeation into the DEMO Coolant from the Li17-Pb Blanket by Reiter. 
Hydrogen embrittlement of alloys is another limiting factor associated with permeation factors as described by Jones for $\mathrm{HT}^{33}$ (Figure 5). The impact of barriers on the concentration of hydrogen in fusion structural materials has received limited treatment, although Reiter's treatment without $(n, p)$ reactions indicates that barriers will dramatically increase the hydrogen concentration in the structural material of his DEMO design. Simunen ${ }^{34}$ has considered hydrogen isotope buildup in layered first wall structures which included stainless steels as the structural component, again without internal (n,p) generation; and found concentrations above the ppm levels that Jones would predict to be important to crack growth rates in ferritic alloys. In contrast, experimental evidence of bulk hydrogen concentrations below $500 \mathrm{ppm}$ in austenitic stainless steels revealed a threshold stress inten sity for subcritical crack growth. In austenitic stainless steels, bulk hydrogen must reach several atomic percent in order to decrease ductility. Hydrogen isotopes can affect the mechanical properties of stainless steels by three different mechanisms:

1. Hydrogen enhanced local plasticity occurs in normally ductile alloys such as austenitic and ferritic stainless steels. In the case of crack propagation in hydrogen, the rate of crack growth can be limited by the rate of transport of hydrogen to the crack tip in certain situations. These crack surfaces often appear brittle because of the localized plasticity without long range plasticity of the surrounding material.

2. Hydrogen attack refers to fracture induced by the formation of precipitation of gaseous hydrogen into bubbles in advance of the crack tip. In some cases the hydrogen is proposed to come out of solution as methane or water.

3. Grain boundary decohesion, i.e., segregation of solute to the grain boundaries, can result in hydrogen-enhanced intergranular fracture.

Alloys such as $\mathrm{V}$ and $\mathrm{Ti}$ have been considered for fusion designs but have negative solution energies and readily getter hydrogen. An additional mechanism for fracture occurs when concentrations of hydrogen isotopes become sufficient for hydride precipitation during fracture. Stress induced hydride formation can occur even if the precipitation would not occur based upon equilibrium 


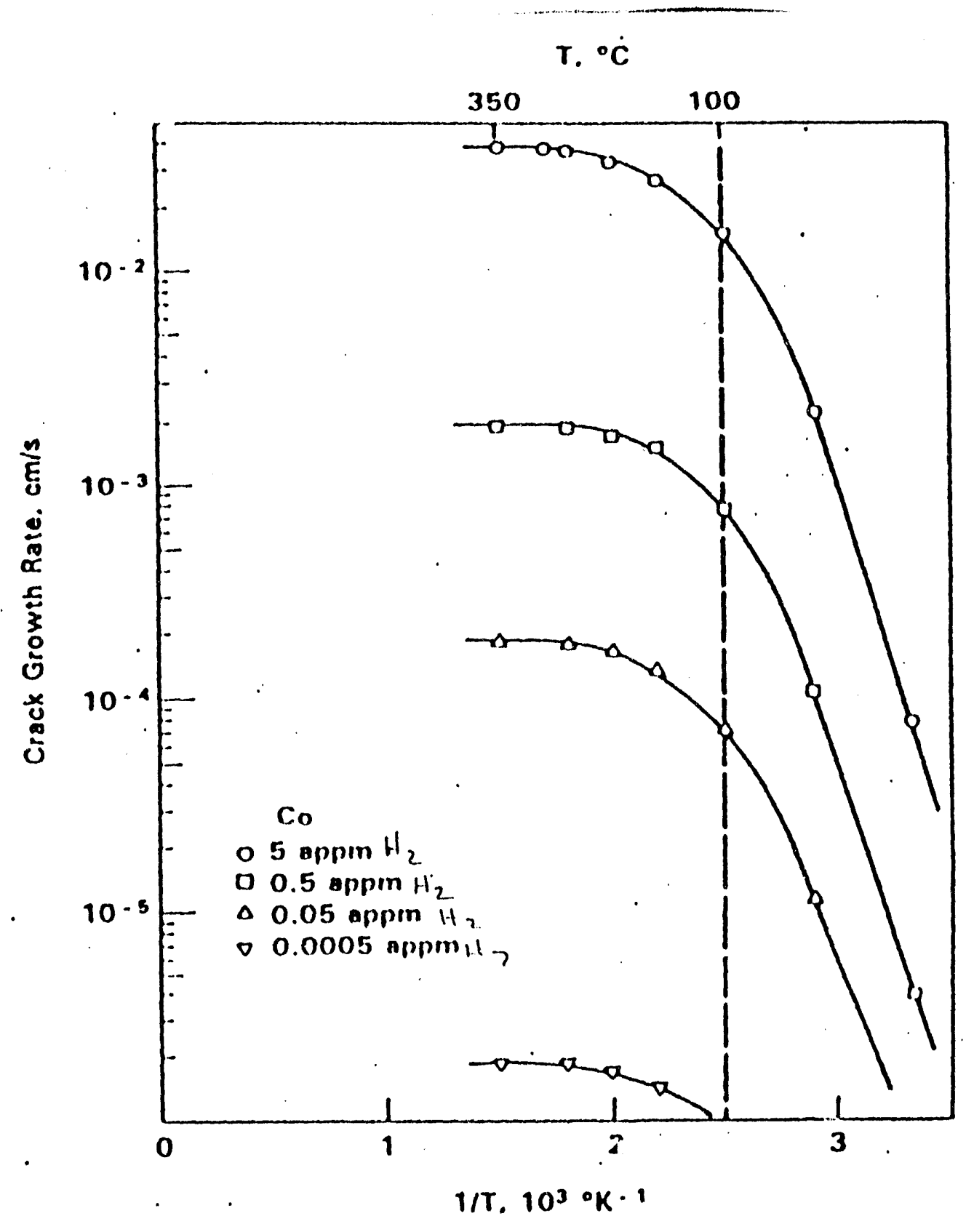

Figure 5. Calculated Crack Growth Rate-1/T Relationship for HT-9 with Variable Steady State Internal Hydrogen Concentrations by Jones. 
thermodynamics. Permeation barrier can be either detrimental or useful for avoiding hydrogen degradation of structural metals.

Mathematical Convention

The mathematical convention for the phenomenon of permeation transport in metals and ceramics breaks down when considering barrier effects. Normally, one considers the expression from permeability to be:

$$
\mathrm{J}=\frac{\Phi A\left(\mathrm{P}^{1 / 2}-\mathrm{p}^{1 / 2}\right)}{\mathrm{t}}
$$

where $\mathrm{J}$ is the flux of hydrogen, $\Phi$ is the permeability (i.e., the product of diffusivity and soluibility), $\mathrm{A}$ and $\mathrm{t}$ are the working area and thickness of the material, and $\mathrm{P}$ and $\mathrm{p}$ are the upstream and downstream summed, hydrogen isotopic pressures. The issue in application of this approach to thin barrier coatings is first that the thickness, $t$, is an indeterminant parameter in most cases and secondly that a completely different mechanism may be applicable. The permeability of hydrogen isotopes is usually thought to be inversely proportional to the square route of the mass of the isotope, i.e $\sqrt{ } 1, \sqrt{ } 2$, $\sqrt{ } 3$.

Some authors take the liberty to define a parameter entitled the "permeation reduction factor", i.e., PRF, which is simply the ratio of the permeation rate of the hydrogen isotope without a barrier coating to that with the barrier coating in place. Although the parameter is useful when considering a specified component with a specified substrate metal, it is intractable in general usage. Other authors avoid the conflict entirely by presenting essentially raw data in terms of permeation rate, J/A, at specified barrier/metal thicknesses and hydrogen partial pressure differences. 


\section{Aluminized Coatings}

The utilization of aluminized coating as permeation barriers was a natural evolution of previous work on oxide coatings. Several researchers realized that iron-based alloys containing aluminum generated more suitable oxide barriers to hydrogen diffusion. Van Deventer ${ }^{36}$ and then McGuire ${ }^{1}$ were some of the earliest experimenters to actually measure significant permeation reductions with aluminized stainless steel with the intent of limiting tritium release from liquid metal breeder reactor coolant systems. More recently Forcey ${ }^{2,3}$ and Gilbert ${ }^{5}$ and their coworkers have refined both the manufacturing and mechanistic understanding for aluminized coatings on 300 series stainless steels. Aluminized coatings are defined as aluminum-based intermetallic coatings generated by the controlled diftusion of aluminum into the substrate metal such that a gradient in aluminum content is generated from the base metal composition from 38 to $80 \mathrm{wt} \%$ aluminum at the surface. Aluminum deposition onto the substrate metal can be accomplished by a variety of techniques: dipping into molten aluminum, precipitation from liquid metals, flame spraying, vacuum plasma spraying, ion-implantation, chemical vapor deposition (CVD), sputter CVD and packed-bed (cementation) techniques. The packed-bed technique has been developed and commercially deployed by aerospace manufacturers for applications involving wear and corrosion. As Forcey and Thompson pointed out, the component to be coated is immersed in a powder compact consisting of alumina, aluminum and ammonium chloride. As the bed is heated with an inert gas cover, aluminum chloride gas forms and transports aluminum to the component surface where it diffuses inward to form intermetallics such as $\mathrm{FeAl}, \mathrm{FeAl}_{2}, \mathrm{Fe}_{2} \mathrm{Al}_{5}$ and $\mathrm{FeAl}_{3}$. Furthermore, the coating appears to form as two distinct layers: an outer layer which is primarily the higher aluminides, and a multi-phase inner layer which provides a gradient in aluminum (Figure 6). 


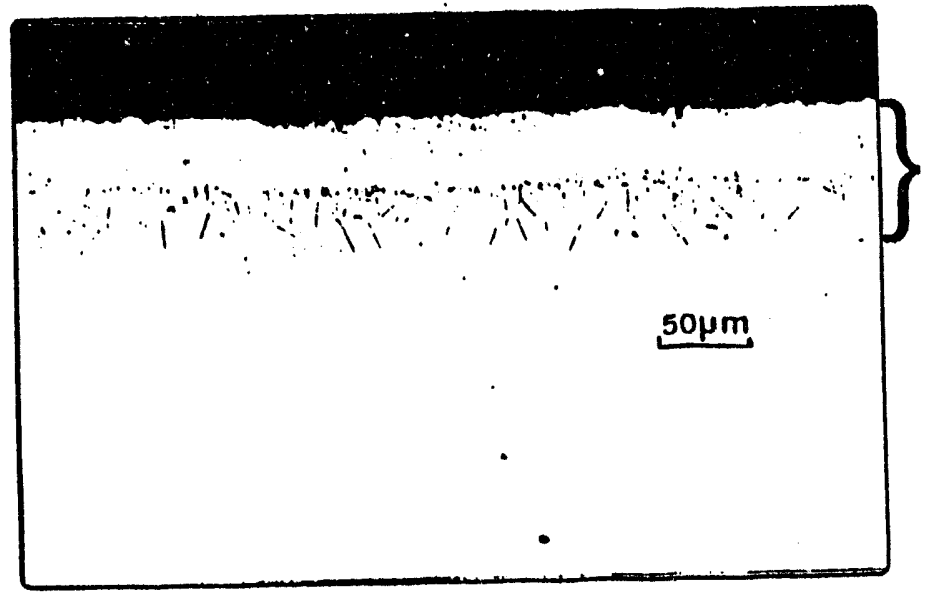

\section{Aluminide Coating}

\section{L Steel Substrate}

Figure 6. Aluminide Coating on 316L Obtained by Packed-cementation Process Exhibiting Two Distinct Layers.

The diffusional process which leads to intermetallic formation is sometimes operated at temperatures between 850 to $950^{\circ} \mathrm{C}$. Hence, metals which require specialized heat treatments, i.e., HT-9 and MANET, may not be viable candidates for conventional packed-bed aluminizing. In addition, aluminizing must either be accomplished after welding or else the aluminizing must be ground off in the regions adjacent to the welds. This unprotected area on the surface must then be addressed by another technique. Finally, packed bed aluminizing is chloride-based, an element that has been strictly avoided from a stress corrosion standpoint in nuclear grade components.

In Figure 7, permeation rates $\left(\mathrm{H}_{2}\right.$ and $\left.\mathrm{D}_{2}\right)$ of aluminized austenitic stainless steel tubes at $101 \mathrm{KPa}$ from several authors are presented. It was necessary to extrapolate the data of McGuire and Gilbert on the basis of the uncoated data for $3165 S$ of Van Deventer ${ }^{36}$ in order to compare it to the others. In addition, aluminized disc data from Forcey is also included in the lower left with oxide coatings. The available permeation data on $\mathrm{Al}_{2} \mathrm{O}_{3}{ }^{22}$ has been extrapolated from high temperatures down to this low temperature region for a very thin alumina layer (< monolayer); a questionable, but yet revealing 


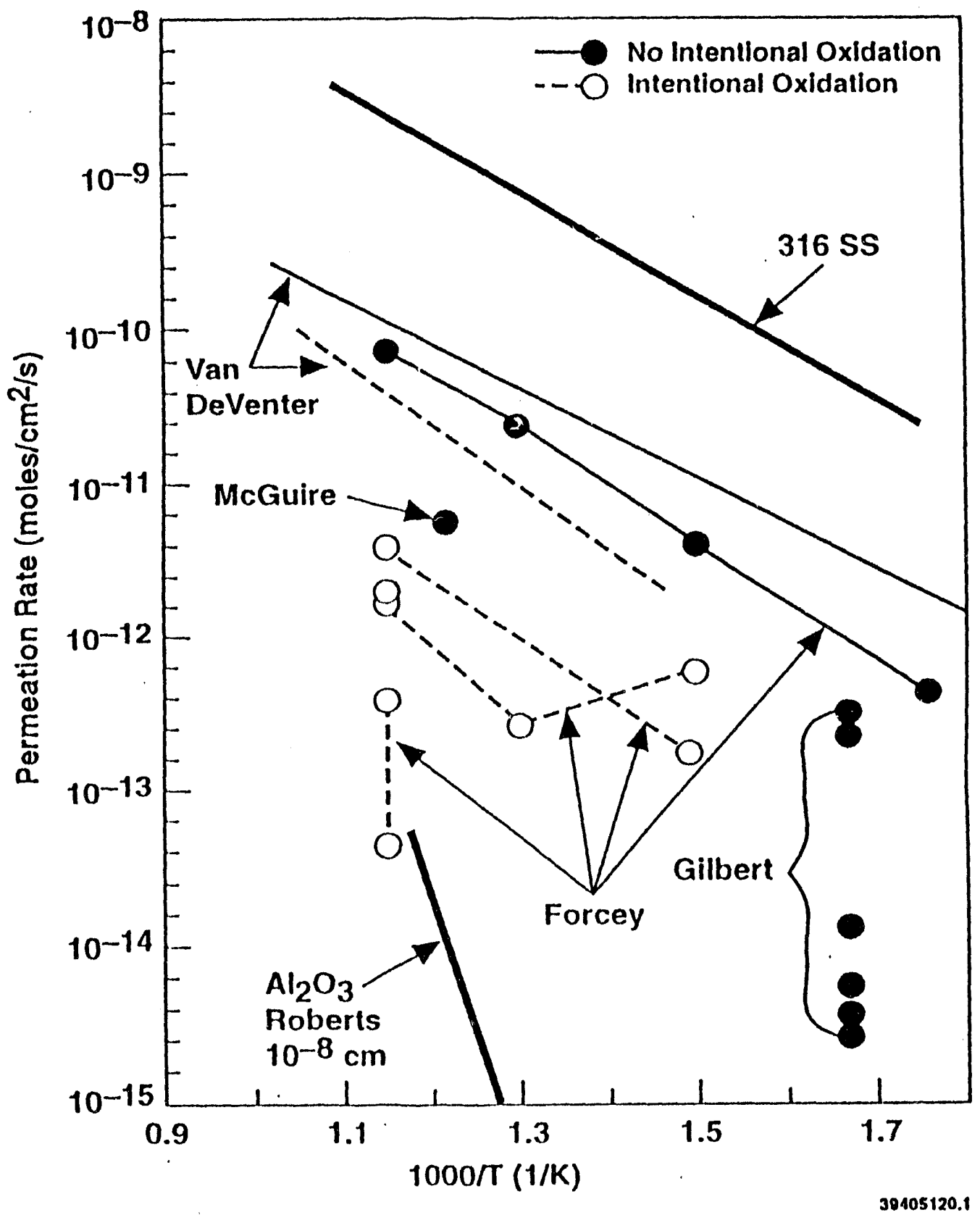

Figure 7. Comparison of Ilydrogen Permeation Rates through Aluminized Austenitic Stainless Steels at $101 \mathrm{KPa}$. Both Oxidized and Unoxidized Measurements are Shown.

Extrapolated Values for Uncoated Stainless Steel and a Very Thin Sheet of $\mathrm{Al}_{2} \mathrm{O}_{3}$ are Also Shown. 
addition, aluminized disc data from Forcey is also included in the lower left with oxide coatings. The available permeation data on $\mathrm{Al}_{2} \mathrm{O}_{3}{ }^{22}$ has been extrapolated from high temperatures down to this low temperature region for a very thin alumina layer (< monolayer); a questionable but yet revealing procedure. It is accepted that the extrapolation of the $\mathrm{Al}_{2} \mathrm{O}_{3}$ data to lower temperatures may lead to significant underestimation of the permeability because of the change in mechanism from bulk to either grain boundary or defect diffusional mechanisms. Such a change could lead to a several orders of magnitude increase. However, the rermeability of $\mathrm{Al}_{2} \mathrm{O}_{3}$ is so low that these uncertainties are not considered important in the comparison. The extrapolation of McGuire's data to $101 \mathrm{KPa}$ was done on the basis of Sievert's law dependence on pressure, as will be discussed later. The uncoated 316L permeation rates of Forcey ${ }^{37}$ shown are almost identical to those of Van Deventer's uncoated data on the scale of this graph. Obviously, a very thin coating of $\mathrm{Al}_{2} \mathrm{O}_{3}$ provides more than enough of a diffusional barrier to obtain PRFs of more than 10,000 .

The coating parameters for these studies are listed in Table I. The data is typically taken with a coated tube containing hydrogen or deuterium pressurized to less than an atmosphere on one side and a vacuum on the other. The permeating flux is either measured by the rate of pressure decline on the interior, pressure increase on the exterior or by a mass spectrometer on the exterior of the tube. Several authors indicated that permeation rate tended to decrease during the measurements, presumably from in situ oxidation of the coating. Even at low oxygen partial pressures, aluminum metal can oxidize by reducing gaseous species such as carbon dioxide, carbon monoxide or moisture.

The data of McGuire and Gilbert and some of Forcey's data were evidently taken in the "un idized" condition, or rather unintentionally oxidized condition. The "unoxidized" data of Forcey and Van Deventer that span a wide temperature range are higher than those of McGuire and Gilbert. In Table l, it can be seen that the aluminized coatings of Forcey were intentionally selected to be at a lower aluminum content than the other authors. The specimens prepared by Van Deventer are the 
only ones that are not from a packed aluminized process. He used sputtering to achieve a $4 \mu \mathrm{m}$ aluminum coating with evidently some subsurface formation of aluminides in the process.

In Figure 8, the date of Gilbert, which spans a large range of aluminum to metal ratios ( 0.42 to 4$)$, demonstrates the importance of this parameter in affecting "unoxidized" permeability. The higher permeation rates of Gilbert (low Al/M ratio coating) in Figure 7 are within a factor of 5 of those of Forcey, which also had low $\mathrm{Al} / \mathrm{M}$ ratios. In Figure 8, the relationship between permeability and aluminum content demonstrates the importance of this parameter in comparison to barrier thickness at high $\mathrm{Al} / \mathrm{M}$ ratios. At lower $\mathrm{Al} / \mathrm{M}$ ratios there may be a far greater dependence on thickness; however, sufficient data is not available to determine this dependence.

In Figure 7, Forcey has reported in two separate studies the permeability of intentionally oxidized aluminized coatings. The open circle data points were taken on the same tube as the "unoxidized" work in Figure 7 after oxidation at $600^{\circ} \mathrm{C}$ for $10 \mathrm{~min}$. and from an earlier study by Forcey. The oxidized data of Forcey represented by the triangles is from an earlier study when oxidation occurred

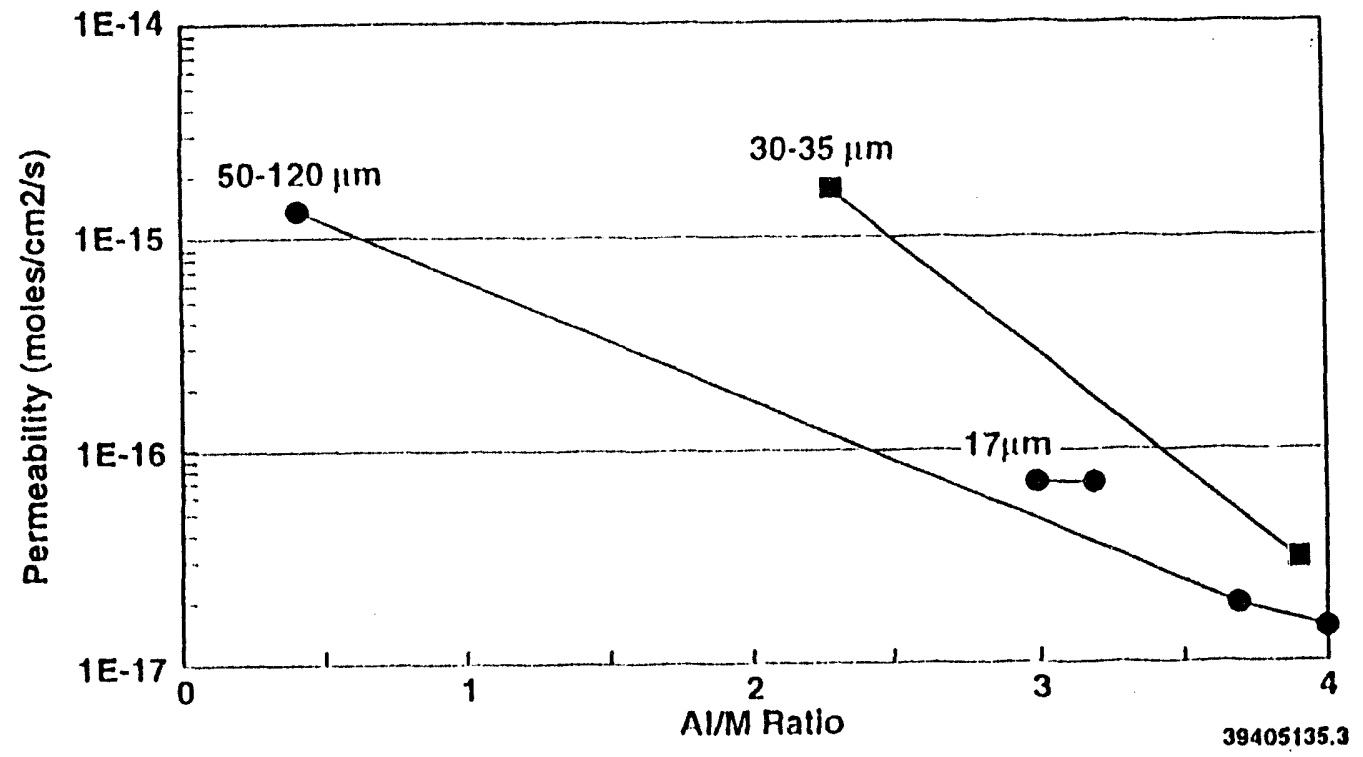

Figure 8. The Effect of $\mathrm{Al} / \mathrm{M}$ Ratio at the Surface of an Aluminized 316 Stainless Steel Tube on the Measured Permeability after Gilbert. 
as a part of fabrication. Finally, the two data points at $600^{\circ} \mathrm{C}$ in the lower left corner of Figure 4 represent an experiment in which Forcey intentionally oxidized a disk and carefully measured the thickness of the oxide coating. The reduction in permeation he measured was not linearly related to the thickness of the coating as one would expect if simple composite permeation were the mechanism. Comparison of the permeation rates of Forcey and those extrapolated from Roberts for aluminum oxide indicate that in almost all these studies, aluminum oxide coatings far thinner than those measured by Forcey wuuld account for the measured permeation rates. Forcey actually was able to measure the decrease in permeation rate as he oxidized the specimen over a time period of 1 day. As the thickness increased from $0.03 \mu \mathrm{m}$ to over $1.4 \mu \mathrm{m}$, the permeation rate dropped by an order of magnitude.

In addition, it should be noted that the activation energies observed by Forcey, which are qualitatively supported by the data of Gilbert and McGuire remain essentially unaffected by the application of the "unoxidized" coating and subsequent oxidation. The activation energy for permeation through alumina at higher temperatures was $318 \mathrm{Kj} / \mathrm{g}$-atom while that for stainless steel is only about $65 \mathrm{Kj} / \mathrm{g}$-atom. If the rate controlling process is diffusion through the alumina layer then the extrapolated activation energy for permeation of alumina would be expected; however, the observed activation energy for barriers does not appear to change. On the other hand if the rate controlling permeation mechanism is still due to diffusion through the stainless steel, these observations are consistent with the observed data. However the large reduction in permeation rate with the addition of the coating must also be incorporated into this interpretation.

In addition to $316 \mathrm{SS}$, Forcey ${ }^{2}$ also applied aluminized layers to a martensitic alloy, DIN 1.4914 (MANET) by the cementation process. Because MANET steel possesses almost an order of magnitude larger initial permeability than $316 \mathrm{~L}$, even greater barrier effectiveness would be desired. Unfortunately, Forcey found a limited improvement in the effectiveness of the coating with only 2 
orders of magnitude reduction in some cases with perhaps 3 orders of magnitude improvement after oxidation was accomplished. Hence, the permeability of aluminized MANET is expected to be higher than that of equivalent austenitic steels, albeit the coating composition and metallurgy will not be exactly similar. Since the packed-bed aluminizing process would interfere with the unique heat treatments required for MANET steel, Perujo" has provided an alternative method of aluminizing based upon deposited aluminum. Perujo was able J apply a $100 \mu \mathrm{m}$ thick aluminized coating by vacuum plasma spraying of aluminum followed by the standard thermal treatment to this alloy and achieved an $\mathrm{Al} / \mathrm{M}$ ratio as high as 3 . The layer was described as being quite brittle since a large number of cracks were found on the surface. Nevertheless, the coating reduced the deuterium permeation by a factor of approximately 1000 between 300 and $500^{\circ} \mathrm{C}$ for an upstream pressure of $50 \mathrm{Kpa}$ as shown in Figure 9.

Thompson ${ }^{(9)}$ applied both implanted and cementation coatings of aluminum to nickel substrates and was able to achieve PRFs of 2 and 50 respectively at temperatures between 350 and $550^{\circ} \mathrm{C}$. Muhlratzer ${ }^{(8)}$ was able to achieve PRFs of 20 to 1000 by attempting to apply a CVD $\mathrm{Al}_{2} \mathrm{O}_{3}$ coating to Hastelloy-X with a variety of interlayers, but by controlled oxidation of the substrate metal he was able to achieve even better results.

The dependence of permeation rate on hydrogen isotope partial pressure is not only important from the fundamental standpoint of mechanism determination but also from the technology focus of extrapolating measurements taken at $100 \mathrm{KPa}$ down to very low partial pressures. Three mechanisms which have been considered for barrier rate controlling steps are shown in Figure 10.

1. Composite Diffusion Model. The simplest mechanism is that associated with a simple model of permeating through a layered composite with one material possessing vastly different permeability than the other as was formulated by Forcey. 


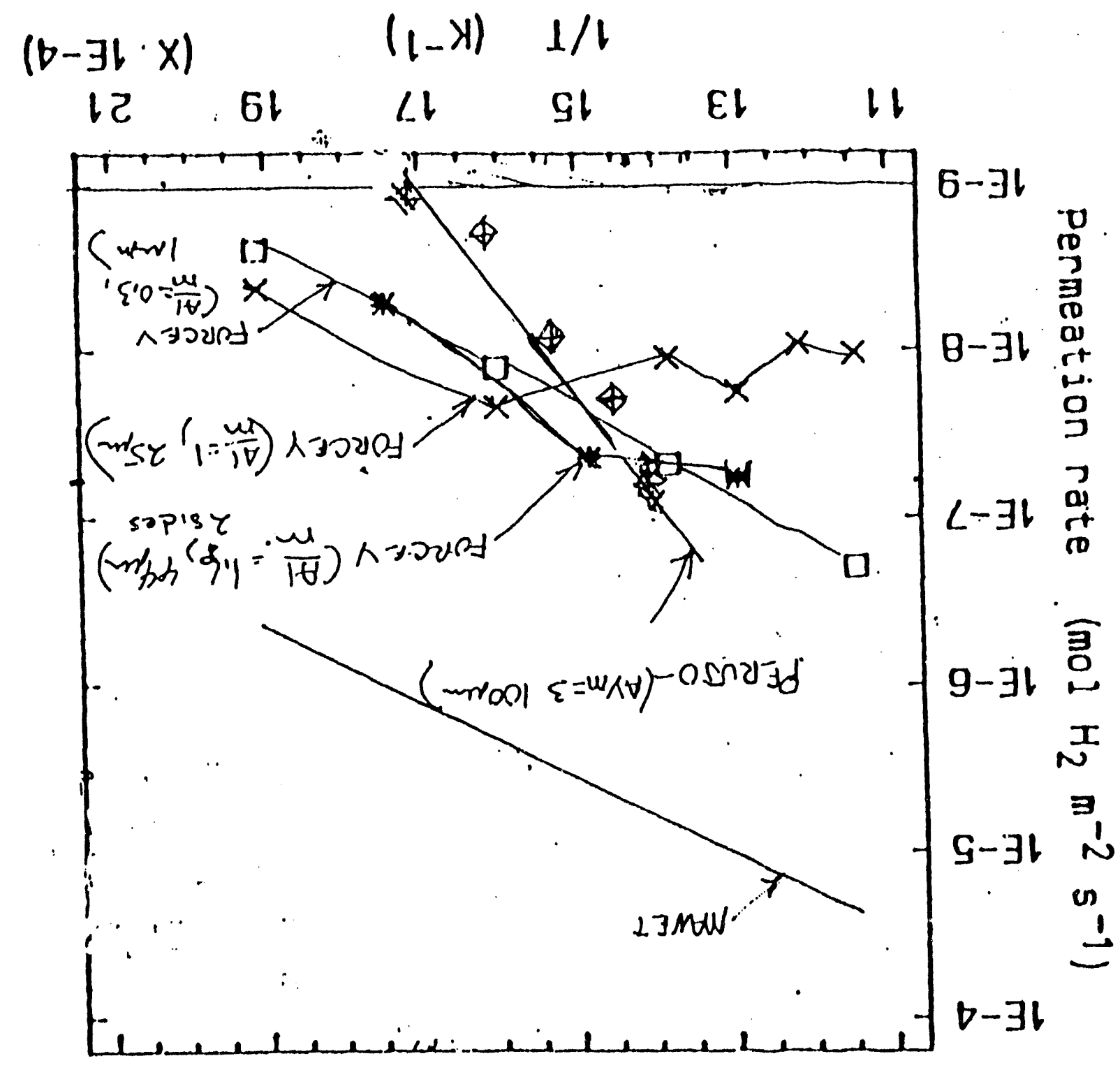




\section{Composite \\ Permeation Model}

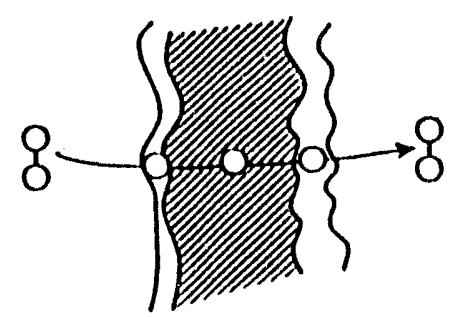

$J=\frac{A P^{1 / 2}}{\left(d_{B} / P_{B}+d_{m} / P_{m}\right)}$

Areal-Defect Model

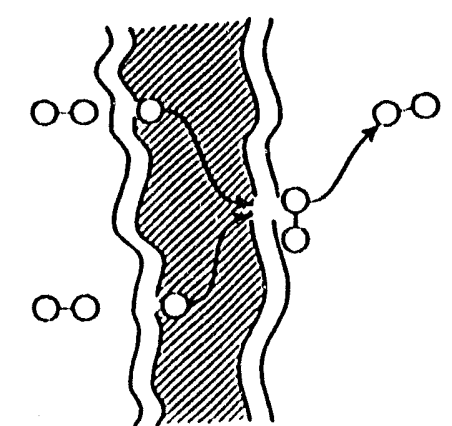

$J=\frac{P_{m} A_{d} G P^{1 / 2}}{d_{e f f}}$
Surface Limited

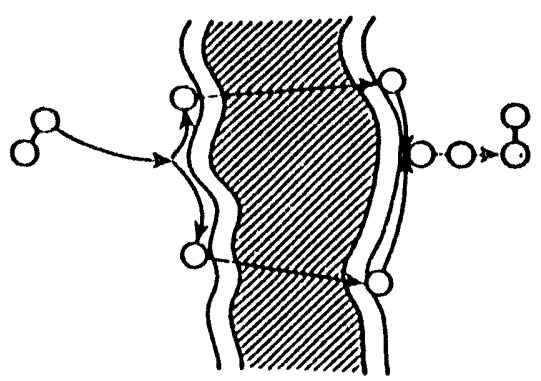

$J_{1}=K_{1} C_{1}{ }^{2}$

$$
J_{2}=K_{2} P
$$

39405135.4

Figure 10. Three Mechanisms for Permeation Through Barrier Coated Metals.

2. Area Defect Model. $\Lambda$ derivative of the composite permeation model suggested by Forcey and Gilbert is the Area Defect model in which the barricr is nominally considered impermeable while all hydrogen transport occurs through a limited number of defects. While the Composite Permeation Model is controlled by diffusion in the barrier, the Area Defect model is actually controlled by diffusion in the bulk metal at a limited number of sites.

3. Surface Desorption Model. The third mechanism is more difficult to image, in that it represents a surface limited case in which recombination effects on the downstream side control the rate of permeation through the composite. The interpretation of this mechanism for a barrier on the upstream surface is particularly difficult to visualize. In comparison to the 
In examining the ex-reactor data discussed here there appear to be two very important observations related to mechanism. First, the activation energies observed in these high pressure studies appear to remain the same as that of permeation through the base metal. The qualitative examination of

Figure 7 leads one to associated permeation in the barrier coated, both oxidized and "unoxidized" with permeation in the base metal rather than in the high activation energy of the alumina. Hence, this observation tends to support the areal defect model discussed above which provides the appropriate activation energy. This focus on areal defects caused Gilbert to develop an eddy current technique for nondestructive examination of his barrier coated 316SS tubes. Eddy current testing provides a response sensitive to both integrity of the ferritic aluminide phases and their thickness. In Figure 11, other two mechanisms, recombination-controlled permeation rates would be expected to possess a partial pressure dependence of 1 rather than $1 / 2$. The wide variation in barrier response to the eddy

\section{Unacceptable Coating}

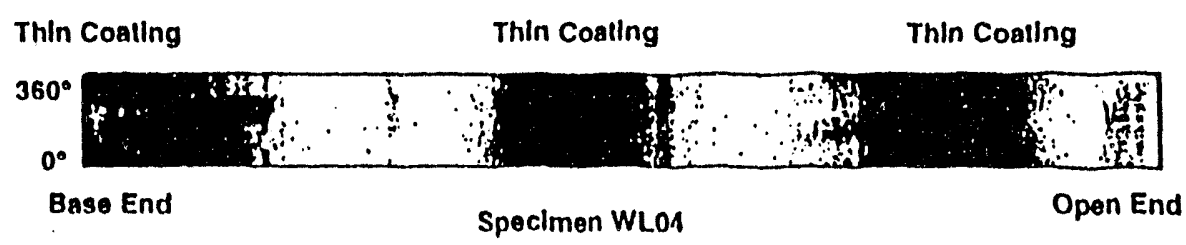

\section{Acceptable Coating}

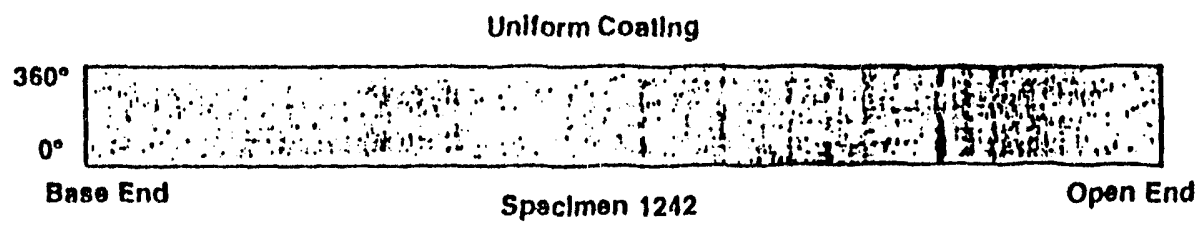

30110022.24

Figure 11. Eddy-Current Characterization of Two Tubes Which are 1.3 Meters Long; One Tube Indicates a Wide Range in Eddy Current Response, While the Other Indicates a Homogeneous Coating After Gilbert. 
current testing in the $4 \mathrm{ft}$. long WL04 tube as compared to the uniformity in 1242 tube was manifested in tritium permeation rates measured in autoclaves at $330^{\circ} \mathrm{C}$ in Figure 12 . The permeation of tritium out of the WL04 tube with its highly defective barrier was only an order of magnitude lower than that of an uncoated tube. However, the highly uniform 1242 tube barrier coating permitted a permeation which was 3 orders of magnitude lower. This emphasizes the importance of NDE as a tool for a successful hydrogen barrier coating.

The partial pressure dependence exponent of 0.46 reported by Forcey ${ }^{2}$ for aluminized stainless steel is consistent with either the Composite Permeation or Area Defect model since both are dominated by Sievert's law at pressures from 1000 to $10,000 \mathrm{~Pa}$. In contrast, McGuire reported that the coating modified the Sievert's law dependence of uncoated stainless steel $(0.5)$ to an exponent of 1.1 in the region of 200 to $1000 \mathrm{~Pa}$. Perujo, et al., actually found a 0.5 pressure exponent above $20,000 \mathrm{~Pa}$ like Forcey $^{2}$ and a singular dependence below $20000 \mathrm{~Pa}$ on a MANET steel. These results taken as a group indicate that an Area Defect mechanism could be controlling at high transport rates (i.e., pressures) while a Surface Limited mechanism would be controlling at low pressures and transport rates. Corsidering that at high permeation rates many hydrogen atoms are available on the downstream surface, it is not logical to expect that a surface limiting phenomenon, like recombination, would not be rate controlling. A surface limiting phenomenon is much more likely when the number of hydrogen-filled surface sites are few, such as at low pressures where the permeation rate is low. On vacuum testing an oxidized steel sample, Swansiger ${ }^{15}$ appeared to verify the importance of these surface effects by application of palladium coating on the oxide which eliminated its order of magnitude reduction of permeability, presumably by elimination of the recombination limiting process. Finally, if the surface desorption model is applicable, even at low partial pressures, it is questionable whether these lat oratory environmental conditions are prototypic to fusion reactors. Barriers are not being considered: as such for first wall locations (vacuum). If barriers are positioned next to coolant streams (water or liquid metals) or next to solid breeder blankets surface recombination effects are not 


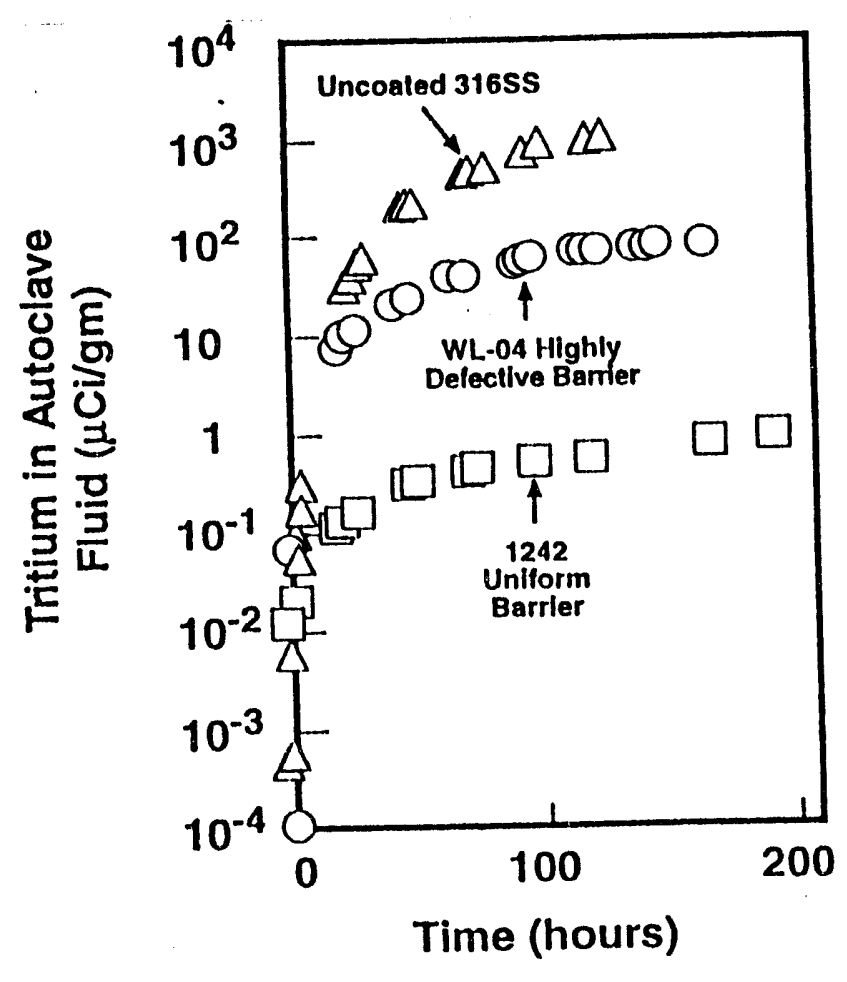

$39404120.1 \mathrm{~b} / \mathrm{w}$

Figure 12. Correlation of Tritium Permeation Measurements in an Autoclave with Eddy Current Measurements in Figure 11 After Gilbert

anticipated because of the presence of hydrogen on surface sites or the lack of a recombination for liquid metal entry.

Other Barriers

The greatest interest, and success, for non aluminum-based barrier coatings has been with titaniumbased coatings. Titanium carbide and nitride can readily be deposited by various CVD and plasma spraying techniques ${ }^{38}$. The CVD processing can alternatively be conducted by sputtering of the titanium metal rather than a volatile titanium compound. The surface formed by these depositions is 
not as metallurgically intimate as the aluminide but has been demonstrated to possess excellent adhesion capabilities.

In Figure 13, the deuterium permeation rates observed by Forcey ${ }^{11}$ on these materials are compared to a recent set of tritium permeation measurements of Shan ${ }^{10}$. Forcey applied two CVD coatings of 1) $\mathrm{TiN}(1.5 \mu \mathrm{m}) / \mathrm{TiC}(1.5 \mu \mathrm{m})$ and 2$) \mathrm{Al}_{2} \mathrm{O}_{3}(4 \mu \mathrm{m})$ over a TiC/TiN bilayer. In contrast Shan apparently deposited a $0.01 \mu \mathrm{m}$ thick titanium metal layer prior to depositing either a TiC $(2.5 \mu \mathrm{m})$ or alternatively generated a $\mathrm{Ti}(0.01 \mu \mathrm{m}) / \mathrm{TiN}(1 \mu \mathrm{m}) \mathrm{TiC} / \mathrm{TiN}$ composite $(2.5 \mu \mathrm{m})$ film. Although Forcey reported only one order of magnitude reduction in permeation, Shan reported almost 6 orders of reduction in the tritium permeation rate through his composite coatings. One perspective on these drastically different results might be to assume as Forcey ${ }^{11}$ did that permeation in these systems is dominated by the presents of defects in the coatings. In this simplified view, Shan simply fabricated a coating with a reduced defect size and population. Although extensive details are not presented, Shan's results infer a high level of chemical reactivity during testing at both low and high temperatures with the inference of hydrocarbon formation/oxidation. No mention of the anticipated effects of a strong getter, titanium, in Shan's complex situation are discussed. Evidently, titanium compounds can form very effective barriers to hydrogen isotope permeation and are easily deposited. Obviously, more extensive evaluation of the potential of titanium-based coatings for tritium permeation barriers is warranted but with a more dedicated examination of the mechanism dominating the transport.

Considering the permeation reductions attributed to chromia on oxidized metals, a logical extension is to attempt to gain further benefit by enriching the surface through chromia coatings. Terai ${ }^{14}$ applied a specific type of chromia coating to 316 stainless steel via a $\mathrm{SiO}_{2}$ slurry deposition, followed by a chemical densification with chromia, and firing at $450^{\circ} \mathrm{C}$. Terai points out the same feature of chromia that is evident by Tanabe ${ }^{19}$, i.e., that in a reducing environment (such as lithium-lead alloys) 


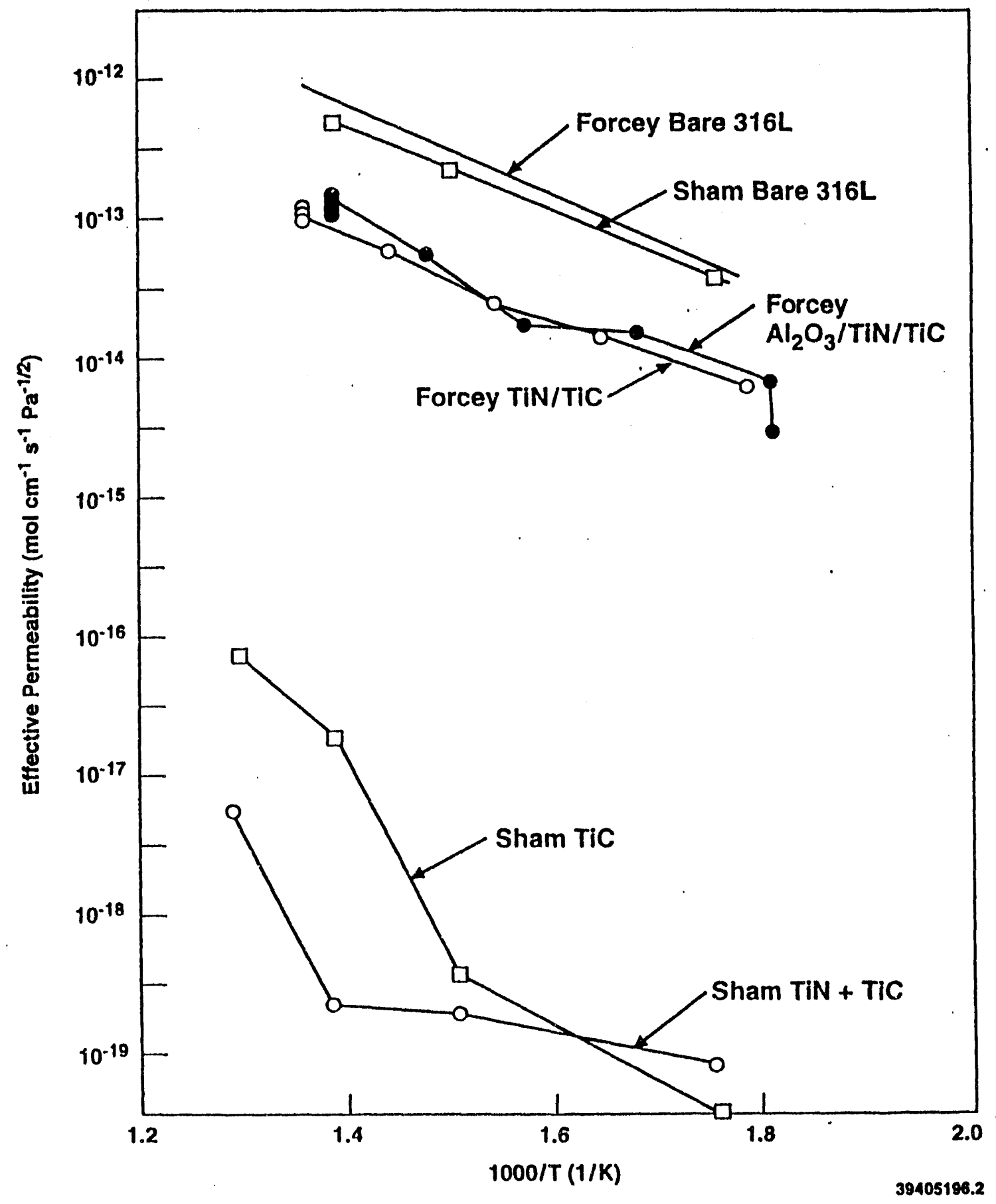

Figure 13. Comparison of the Measured Permeabilities for Hydrogen Isotopes in TiN and TiC Coated 316L, Stainless Steels. 
that chemical reduction of the chromia metal is anticipated. Approximately one order of magnitude decrease in the permeability is anticipated from their result which will be discussed in the section on irradiation testing.

Corrosion, Irradiation and Mechanical Degradation of Barrier Coatings

The current consensus is that irradiation and corrosion effects will reduce but not eliminate the effectiveness of hydrogen isotope barriers. Because some irradiation testing normally attempts to simulate the engineering environment, many of the tests simultaneously included corrosion irradiation, and mechanical degradation. It would seem that the simplest type of irradiation testing is to duplicate the laboratory permeation test in the confines of an irradiation environment, but no barrier testing has been conducted in this manner. Polosuhin, B. G. ${ }^{39}$ and Kalinin ${ }^{39}$ have reported on this type of in-reactor testing in which the permeation rate of austenitic stainless steel (without an intentional barrier) increased approximately a factor of 3 to 10 under neutron irradiation but without barriers in place. In addition, there are those that infer that hydrogen can be trapped in structural metals at irradiation defects. The impact on this phenomenon on barrier or base metal permeation may not be dramatic since these atoms are by definition trapped in the lattice and not mobile.

In Table IV, several irradiation tests are listed in which tritium/hydrogen barriers have been evaluated in an engineering environment. The LIBRETTO and TREXMAN irradiation experiments were conducted with molten lithium-lead directly in contact with either the barrier or else the metal substrate supporting the coating as shown in Table V. An important discriminating factor in these tests is the location of the barrier since, as was pointed out earlier, the molten metal can corrode the oxide film. In the TREXMAN experiment a vivid example of this is shown since the chromia coating next to the molten alloy led to an ineffective barrier (PRF), while when it was on the exterior an effective PRF of almost 100 was achieved. In the case of the LIBRETTO experiments, the TiC and 
CVD $\mathrm{Al}_{2} \mathrm{O}_{3}$ coatings only exhibited an effective PRF of 3 while the aluminizing coating appeared to possess a coating of 15 to 80 .

Table IV. Parameters for Austenitic Stainless Steel Aluminized Coatings

\begin{tabular}{lllc} 
Author & $\begin{array}{l}\text { Aluminized } \\
\text { Thickness }\end{array}$ & $\begin{array}{l}\text { Metal } \\
\text { Thickness }(\mu \mathrm{m})\end{array}$ & Al/M Ratio \\
\hline \hline Van Deventer & $4 \mu \mathrm{m}$ & 0.13 & Pure Al \\
McGuire & 40 one side & $0.04304 \mathrm{SS}$ & $>2$ \\
Forcey Tubes (91) & $275-330$ both sides & $0.2316 \mathrm{~L}$ & 0.5 \\
Forcey Disks (91) & 30 both sides & $0.16316 \mathrm{~L}$ & 0.9 \\
Forcey Disks (89) & -- one side & $0.16316 \mathrm{~L}$ & $>2$ \\
Gilbert & $17-120$ one side & $0.05316 \mathrm{SS}$ & 0.42 to 4 \\
\hline \hline
\end{tabular}

In examining these relatively low permeabilities in comparison to laboratory experiments, there are three possible causes: implantation, corrosion, and irradiation effects. In the specific geometry for LIBRETTO, implantation could limit the transport on barriers adjacent to the molten metal to a PRF of approximately 400 , evidently not the dominant effect in these tests. Although capsule tests of various ceramics in contact with liquid $\mathrm{Li} 17-\mathrm{Pb}\left(800^{\circ} \mathrm{C}, 62\right.$ days) indicated no interaction with $\mathrm{MgO}$, $\mathrm{SiC}$, TiN and $\mathrm{ZrC}$ with the liquid alloy; $\mathrm{Al}_{2} \mathrm{O}_{3}$ was found to form $\mathrm{LiAlO}_{2}$ and $\mathrm{LiAl}_{5} \mathrm{O}_{8}{ }^{46}$. Whereas, compatibility tests performed with aluminide coatings (obtained by packed cementation) in liquid $\mathrm{Li17}-\mathrm{Pb}$ indicated no degradation of the coating in the presence of static and turbulent flowing Li17- $\mathrm{Pb}$ for temperatures up to $475^{\circ} \mathrm{C}$ for 125 days ${ }^{47-49}$. In addition, even hot-dipped aluminized specimens (1.4914 martensitic steel) do not exhibit visible damage in the aluminide layer ${ }^{50}$ after 250 days in flowing $\mathrm{Li17}-\mathrm{Pb}$ at $450^{\circ} \mathrm{C}$. Detailed examination of the alumina surface coating is more difficult after these exposures. It is not possible to estimate the deterioration in the PRF due to corrosion, however, since these are anticipated to be low $\mathrm{Al} / \mathrm{M}$ ratio coatings with thin oxide films that were not reported on. 
In two irradiation tests ${ }^{44,45}$, tritium was produced internally in pins by $\mathrm{LiAlO}_{2}$ with barriers used to retain the tritium; the barriers were similar to the high $\mathrm{Al} / \mathrm{M}$ ratio barriers discussed by Gilbert ${ }^{5}$. This configuration loosely reflects the situation of a water-cooled solid breeder blanket. In these two cases both internal and external aluminizing had been conducted. Again the effective PRF of 150 was far short of the 10,000 PRF found in laboratory studies. Again considering implantation, corrosion, and irradiation effects, it is important to note that implantation was precluded because of the zirconium liner between the $\mathrm{LiAlO}_{2}$ and the internal barrier. Severe corrosion of the aluminide coating on the exterior should be considered very likely, although not measured. However, the interior aluminizing treatment should have been unaffected by the external water. Hence, it is speculated that the exterior barriers in these high-pressure, high temperature tests were severely corroded.

Without definitive in-reactor permeation experiments on barrier effectiveness, the effect of irradiation on the transport of hydrogen isotopes through these barriers could be postulated on the basis of irradiation effects on transport in ceramics. Ignoring the potential for gross macroscopic fluence-induced defects (i.e., coating delaminations, helium bubbles, voids, etc.), the most important increase in the hydrogen isotope transport in oxides appears to be the large cross section for the generation of hydroxyl or hydride ions in the oxide to induce radiation induced diffusion (RID). Chen ${ }^{50-52}$ has identified the enhanced mobility, even at room temperature, of hydrogen ions in $\mathrm{MgO}$ and $\mathrm{TiO}_{2}$ because of electron irradiation. In contrast to the irradiation-enhanced mobility in metals, which are dominated by atomic diffusion, in these oxides the diffusion appears to be related to formation of mobile $\mathrm{OH}^{-}, \mathrm{OD}^{-}, \mathrm{OT}^{-}$and $\mathrm{H}^{+}, \mathrm{O}^{+}, \mathrm{T}^{+}, \mathrm{D}^{+}$species. Chen ${ }^{51-53}$ further documented this theme by application of an electrical field which then caused radiation and electric field induced diffusion (REID), in the ceramic monoliths. The rate at which hydrogen or deuterium was transported in these oxides was proportional to the applied voltage while under electron irradiation, even at room temperature. Although Chen has not examined alumina, Roberts ${ }^{54}$ noted high temperature protium ion conduction in single crystal alumina as the mechanism of transport since the permeation rate was 
Table V. Irradiation Testing of Tritium/Hydrogen Barriers

\begin{tabular}{|c|c|c|c|c|c|c|c|}
\hline Test & $\begin{array}{l}\text { Tritium } \\
\text { Source }\end{array}$ & $\begin{array}{l}\text { Tritium } \\
\text { Sink }\end{array}$ & Reactor & $\begin{array}{l}\text { Barrier } \\
\text { System }^{(a)}\end{array}$ & $\begin{array}{c}\text { Temperature } \\
\left({ }^{\circ} \mathrm{C}\right)\end{array}$ & $\begin{array}{c}\text { Effective } \\
\text { PRF }\end{array}$ & References \\
\hline LIBRETTO-2 & $\mathrm{Lil} 7-\mathrm{Pb}$ & $\mathrm{He}+\mathrm{H}_{2}$ & HFR & alum/316L & $275-440$ & $<80$ & $38-39$ \\
\hline LIBRETTO-3 & Lil7-Pb & $\mathrm{He}+\mathrm{H}_{2}$ & HFR & $\begin{array}{c}316 \mathrm{~L} / \mathrm{TiC} \\
\mathrm{AL}_{2} \mathrm{O}_{3} / 316 \mathrm{~L} \\
\text { 316L/alum } / \mathrm{Al}_{2} \mathrm{O}_{3}\end{array}$ & $\begin{array}{l}280-450 \\
280-450 \\
280-450\end{array}$ & $\begin{array}{c}3 \\
3 \\
15\end{array}$ & 40 \\
\hline TREXMAN & Lil 7-Pb & $\mathrm{He}+\mathrm{H}_{2}$ & YAYOI & $\begin{array}{l}\mathrm{Cr}_{2} \mathrm{O}_{3} / 316 \mathrm{SS} \\
316 \mathrm{SS} / \mathrm{Cr}_{2} \mathrm{O}_{3}\end{array}$ & $\begin{array}{c}600 \\
>100\end{array}$ & 1 & 13 \\
\hline Loop-1 & $\mathrm{LiAlO}_{2}$ & $\mathrm{H}_{2} \mathrm{O}$ & ATR & alum/316SS/alum & 318 & 150 & 41 \\
\hline WC-1 & $\mathrm{LiAlO}_{2}$ & $\mathrm{H}_{2} \mathrm{O}$ & ATR & alum/316SS/alum & $<330$ & 150 & 42 \\
\hline
\end{tabular}

(a) The coating listed in the front indicates upstream, for example facing the Li17-Pb alloy. The barrier listed at the end indicates a downstream barrier.

(b) "alum" indicates aluminized layer. In LIBRETTO-3 the surface was oxidized to form $5 \mu \mathrm{m}$ of oxide.

approximately $100 \mathrm{~V}$ even without irradiation. Consequently, for an alumina based barrier it is to be expected that irradiation will result in a greater level of ionized hydroxyl or hydride ion species for conduction. The alarming thought is, of course, that all of the electromagnetic fields in a fusion device will serve to enhance permeation even more than in single static irradiation tests.

A more subtle difference exists between the small laboratory testing of barriers and the in-reactor test which can partially explain the less promising results in Table IV. As pointed out by Gilbert (Figures 11 and 12), the potential for defective coatings on larger parts is always possible in the process scale up required to make irradiation test articles. It is not possible to pinpoint the exact reason for the reduced effective permeation rates in these irradiation tests, but combined or singular effects of corrosion, irradiation-enhanced mobility or fabrication scale-up issues could be at fault. The potential for mechanical degradation of the barriers was emphasized by Perujo ${ }^{43}$ recently when he subjected oxide-coated bellows to repeated flexing while monitoring tritium permeation. In comparison to a stationary inconel bellows he found that flexing resulted in from 1 to 2 orders of 
magnitude higher permeability ${ }^{6}$ Perhaps all components in a fusion plant will not receive such severe mechanical loading, but some loads cannot be avoided. The titanium and aluminide coatings have been developed because of their tendency to form strong bonds with the substrate metals because of the gradient nature of the coating process. Gilbert ${ }^{5}$ pointed out that even though he used a high $\mathrm{Al} / \mathrm{M}$ ratio aluminide coating on $316 \mathrm{SS}$, that in a ring crush test the coating did not fracture until it reached ultimate elongation. Perujo ${ }^{35}$ noted the brittleness of his high $\mathrm{Al} / \mathrm{M}$ ratio coating on MANET led to internal cracks, but subsequently determined that it still possessed excellent PRFs. The high Al/M coatings are considered more brittle than lower $\mathrm{Al} / \mathrm{M}$ coatings ${ }^{2}$. In lower $\mathrm{Al} / \mathrm{M}$ ratio aluminide coatings, Forcey cycled (1000 times) aluminized $316 \mathrm{~L}$ and 1.4914 alloys between 250 and $600^{\circ} \mathrm{C}$ with no visible damage to the coatings and, more importantly, no loss in permeation resistance ${ }^{3}$. Benamati has demonstrated that aluminide coatings (low $\mathrm{Al} / \mathrm{M}$ ) on $316 \mathrm{~L}$ steel have satisfactory behavior under 15,000 cycles in representative conditions of a water-cooled $\mathrm{Pb}-17$ blanket.

\section{Conclusions}

1. Tritium/hydrogen barriers appear to be needed to satisfy fusion nuclear technology issues in many design options, bu $v^{2}$ especially for Li17-Pb blanket options. On the other hand, barriers can potentially increase the degradation of structural materials by their immobilization of hydrogen. In many designs it is desirable to reduce the permeation rate by a factor of over 1000 in comparison to the bare metal.

2. Barriers based upon aluminum (and titanium to a lesser extent) have been demonstrated to provide permeation reduction factors (PRFs) from 1000 to $1,000,000$ in laboratory situations. The rate controlling mechanism may actually be associated with the character and population of defects rather than the intrinsic character of the surface coatings. The coatings appear to be relatively robust, both mechanically and in the presence of Li17- $\mathrm{Pb}$.

3. In-reactor testing has not been able to retain the properties measured in the laboratory with only PRFs of 3 to 150 being reported. The lower PRFs in irradiation testing may be 
associated with RID of hydrogen based upon ionization of the transporting species and some corrosion effects.

4. With no completely satisfactory barrier system in place, it is necessary to continue both fundamental research and engineering demonstration of new barrier systems in order to surmount the challenging problem. A better understanding of the migration mechanism of hydrogen isotopes through these barriers is required, including irradiation effects. The practical problems associated with fabricability and integrated plant design also face the community. 


\section{References}

1. J. G. McGuire, "Hydrogen Permeation Resistance Layers for Liquid Metal Reactors," Conference on Tritium Technology in Fission, Fusion and Isotopic Applications, Dayton, $\mathrm{OH}$ (1980) 64-68.

2. K. S. Forcey, D. K. Ross, and C. H. Wu, "The Formation of Hydrogen Permeation Barriers on Steels by Aluminizing," J. Nucl. Mat. 182 (1991) 36.

3. K. S. Forcey, D. K. Ross, J. C. B. Simpson, D. S. Evans and A. G. Whitaker, "The Use of Aluminizing on 316L Austenitic and 1.4914 Martensitic Steels for the Reduction of Tritium Leakage from the Net Blanket," J. Nucl. Mat. 161 (1989) 108-116.

4. E. H. Van Deventer, V. A. MacLaren and V. A. Maroni, "Hydrogen Permeation Characteristics of Aluminum-Coated and Aluminum-Modified Steels," J. Nucl. Mat. 88 (1980) 168-173.

5. E. R. Gilbert, et al., "Tritium Permeation and Related Studies on Barrier Treated 316 Stainless Steel," Fusion Technology 21 (1992) 739-744.

6. A. Perujo, K. S. Forcey and T. Sample, "Reduction of Deuterium Permeation Through DIN 1.4911 Stainless Steel (MANET) by Plasma Spray Deposited Aluminum," J. Nucl. Mat. 207 (1993) 86-91

7. R. S. Sohki, et al., "Investigation of Aluminized Steel as a Barrier to Tritium Using Accelerator-Based and Hydrogen Permeation Techniques," Nucl. Inst. and Methods in Physics Research, B 40-41 Pt 2 (1989) 780-784.

8. A. Muhlratzer, H. Zeilinger and H. G. Esser, "Development of Protective Coating to Reduce Hydrogen and Tritium Permeation," Nucl. Tech. 66 (1984) 570-577.

9. D. A Thompson and W. W. Smeltzer, "Deuterium and Tritium Diffusion and Permeation Barriers," CFFTP-G-88048, May 1988, CFFTP, Mississauga, Ontario L5J IK3, Canada.

10. Changqi Shan, et al., "The Behavior of Diffusion and Permeation of Tritium through 316L Stainless Steel with Coating of TiC and TiN_TiC, J. Nucl. Mat. Vol. 191-194 Pt A (1992) $221-225$.

11. K. S. Forcey, A. Perujo, F. Reiter, and P. L. Lolli Ceroni, "The Formation of Tritium Permeation Barriers by CVD," J. Nucl. Mat. 200 (1993) 417-420.

12. M. Bonelli, et al., "Study of Hydrogen Diffusion Behavior in PVD Deposited and Ion Bombarded Thin TiN Film Barriers on Nuclear Grade 316L Stainless Steel," Fusion Tech. (1992) 196-200.

13. T. Nelson and G. T. Murray," Prevention of Hydrogen Embrittlement by a $\mathrm{TiO}_{2} \mathrm{Surface}$ Layer," Metal. Trans. 15A (1984) 597-600.

14. T. Terai, T. Yoneoka, H. Tanaka, H. Kawamura, M. Nakamichi, and K. Miyajima, "Tritium Permeation Through Austenitic Stainless Steel with Chemically Densified Coating as a Tritium Permeation Barrier," To be published in J. Nucl. Mat. as part of ICFRM-6. 
15. W. A. Swansiger and R. Bastasz, "Influence of Thin Silicon Films on Deuterium and Tritium Permeation in Steels," Proceedings of Trit. Tech. in Fission, Fusion and Isotopic Applications 91-97 (1980).

16. M. Matsuyama, K. Ashida and H. Miyake, K. Watanabe and Y. Araki, "Adsorption of Tritium on Metal, Ceramic and Organic Materials: Adsorption of Tritium for Stainless Steel," Toyama Daigaki Torichumu Kagaku Senta Kenkyu Hokoku 8, 2245-2256 (1985).

17. J. Bowker and G. R. Pierch, "The Effect of a Thin Barrier Layer on the Permeation of Hydrogen through Mild Steel and Ferritic Stainless Steel," Metall. Trans. A. 15, 2093-2095 (1984).

18. A. M. Brass, J. Chene and J. C. Pivin, "Influence of Nitrogen Ion Implantation on Hydrogen Permeation in an Extra Mild Steel, "J. Mat. Sci. 24 (1989) 1693-1699.

19. T. Tanabe, et al., "Role of Surface Oxide on Hydrogen Transport in Stainless Steel," Fusion Reactor Blanket and Fuel Cycle Technology, University of Tokyo. (1986) 183-186.

20. R. A. Causey, W. R. Wampler, J. R. Rettelle, and J. L. Kaae, "Tritium Migration in Vapor-Deposited $\beta$-Silicon Carbide," J. Nucl. Mat. 203 (1993) 196-205.

21. K. Verghese, L. R. Zumwalt, C. P. Feng, and T. S. Elleman, "Hydrogen Permeation Through Non-Metallic Solids," J. Nucl. Mater. 85 \& 86 (1979) 1161-1164.

22. R. M. Roberts, T. S. Elleman, H. Palour III, and K. Verghese, "Hydrogen Permeability of Sintered Aluminum Oxide," J. Amer. Ceramic Soc. 62 (1979) 495-499.

23. J. H. Austine and T. S. Elleman, J. Nucl. Mat. 43 (1972) 119.

24. M. I. Baskes, DIFFUSE 83, SAND 83-8231, Sandia National Laboratory, Albuquerque, NM, U.S.A.

25. R. T. McGrath, et al., "Design Considerations for ITER Plasma Facing Components," SAND 89-0901. (July 1989) Sandia National Laboratories, Albuquerque, NM USA

26. M. Araki et al., "Analytical and Experimental Evaluations of Simulated Sweeping Heat Load on the Divertor Plate for ITER," Fusion Eng. and Design 22 (1993) 217-227.

27. R. H. Jones, et al., Composite Materials for Fusion Applications, J. Nucl. Mat. 191-194 (1992) 75-83.

28. F. Reiter, S. Tominetti and A. Perujo, Fusion Eng. Des. 15 (1992) 223.

29. D. K. Sze, "An Assessment of Problems Associated with Tritium Containment," Fusion Technology 8, (1985).

30. G. R. Longhurst, "Permeation of Tritium Through Hylife-II Heat Exchanger Tubes EGG-FSP-8678. 
31. K. Radford, "Impact of Hydrogen on the Performance of Stainless Steel-Clad Hafnium in Pressurized Water Reactors," Hydrogene et Materiaux, (Proceedings of the 3rd International Congress on Hydrogen and Materials, Paris, France. (June 1982) Pierre Azou, Permagon.

32. C. Malara, G. Pierini, and A. Viola, "The Feasibility of Tritium Extraction Units from Blanket of Fusion Reactors in the Light of Recent Experimental Data," Fusion Tech. (1993) 1429-1433.

33. R. H. Jones, "Application of Hydrogen Embrittlement Models to the Crack Growth Behavior of Fusion Reactor Materials," J. Nucl. Mat. 141-143 (1986) 468-475.

34. J. L. Brimhall, R. H. Jones, and E. P. Simonen, "Consideration of Tritium and Hydrogen Distribution in Layered Structures for ITER," Fusion Reactor Materials Semiannual Report, DOE/ER-0313/15, February 1994.

35. A. Perujo, K. S. Force, and T. Sample, "Reduction of Deuterium Permeation Through DIN 1.4914 Stainless Steel (MANET) by Plasma-Spray Deposited Aluminum, J. Nucl. Mat. 207 (1993) 86-91.

36. E. H. Van Deventer and V. A. Maroni, "Hydrogen Permeation Characteristics of Some Austenitic and Nickel-Based Alloys, J. Nucl. Mat. 92 (1980) 103-111.

37. K. S. Forcey, D. K. Ross, J. C. B. Simpson and D. S. Evans, J. Nucl. Mat. 160 (1988) 117.

38. F. Brossa, J. Bohdansky, J. Roth and A. P. Martinelli, "TiC Coatings on Stainless Steel, Inconel and Mo: Fabrication and Testing," J. Nucl. Mat. 93 \& 94 (1980) 474-478.

39. B. G. Polosuhin, et al., "Hydrogen Isotope Permeability Through Austenitic Steels Cr18Ni10Ti and Cr16Ni11Mo3Ti During Reactor Irradiation," J. Nucl. Mat. 191-194 (1992) 219-220.

40. G. M. Kalinin, et al., "Experimental Facilities for Investigation of Structural Material Properties for Fusion Reactors Under Irradiation," J. Nucl. Mat. 191-194 (1992) 1363-1366.

41. R. Conrad, "Irradiation Experiments on Liquid Tritium Breeding Material Pb-Lil7 in the HFR Petten," Fusion Engineering and Design 14 (1991) 289-297.

42. E. Proust, P. Leroy and H. W. Fanenberg, "Preliminary Interpretation of the LIBRETTO-2 Experimental Results in Terms of Tritium Permeation Barrier Efficiency," J. Nucl. Mat. 191-194 (1992) 186-189.

43. R. Conrad, M. A. Futterer, L. Giancaril, R. May, A. Perujo, T. Sample, "LIBRETTO-3: Performance of Tritium Permeation Barrier Under Irradiation at the HFR Petten," to be published in J. Nucl. Mat. as a part of ICFRM-6.

44. G. W. Hollenberg, et al., "Simulation of NPLWR Environment in the ATR Loop-1 Test," Proc. 6th Inter. Symp. on Environmental Degradation of Materials in Nuclear Power SystemsWater Reactors (1993) 775-781. Edited by R. E. Gold and E. P. Simonen, TMS, Warrendale, PA.

45. D. D. Lanning, M. M. Paxton, and L. Crumbaugh, "In-Reactor Performance of LWR-Type Tritium Target Rods," Trans. Amer. Nucl. Soc., Vol. 65 (June 1992) 195-197. 
46. V. Coen, H. Kolbe, L. Orecchia, M. Dalla Rossa, High Temperature Corrosion of Technical Ceramics, Elsevier Applied Science (1989).

47. A. Terlain, T. Flament, J. Sannier, J. L. Roualut, "A Study of Permeation Barriers for Pb17Li Breeding Blankets," Fusion Technology 1 (1990) 916.

48. I. Schreinlechner and P. Sattler, "Behavior of SS316 With and Without Aluminization in Stagnant Pb-17Li," J. Nucl. Mat. 191-194 (1992) 97.

49. A. Terlain, T. Dufrenoy, C. Maller, and T. Flament, "Compatibility of an Aluminide Coating of 316L Steel with Flowing Pb-17Li, Technical Report SCECF/251 (March 1992).

50. H. Glasbrenner and H. U. Gorgstedt, to be published in J. Nucl. Mat. from ICFRM-6 Conference, Stressa, Italy (1993).

51. Y. Chen, M. M. Abraham, and H. T. Tohver, "Radiation-Induced Diffusion of Hydrogen and Deuterium in MgO," Phys. Rev. Letters 37 (1976) 1757-1760.

52. Y. Chen, M. M. Abraham, and L. C. Templeton, "Radiation-Induced Mobility of Substitutional Hydrogen in MgO," J. Amer. Ceramic Soc. 60 (1977) 101-104.

53. Y. Chen, R. Gonzalez, and K. L. Tsang, "Diffusion of Deuterium and Hydrogen in Rutile $\mathrm{TiO}_{2}$ Crystals at Low Temperatures," Phys. Rev. Letters 53 (1984) 1077-1079.

54. E. W. Roberts, "Hydrogen Permeability of Alumina in an Electric Field," Science of Ceramics 7 (1973) 319-338.

55. G. Benamati, N. Elmi and M. Agostini, to be published in J. Nucl. Mat. from ICFRM-6, Stressa, Italy (September 1993). 

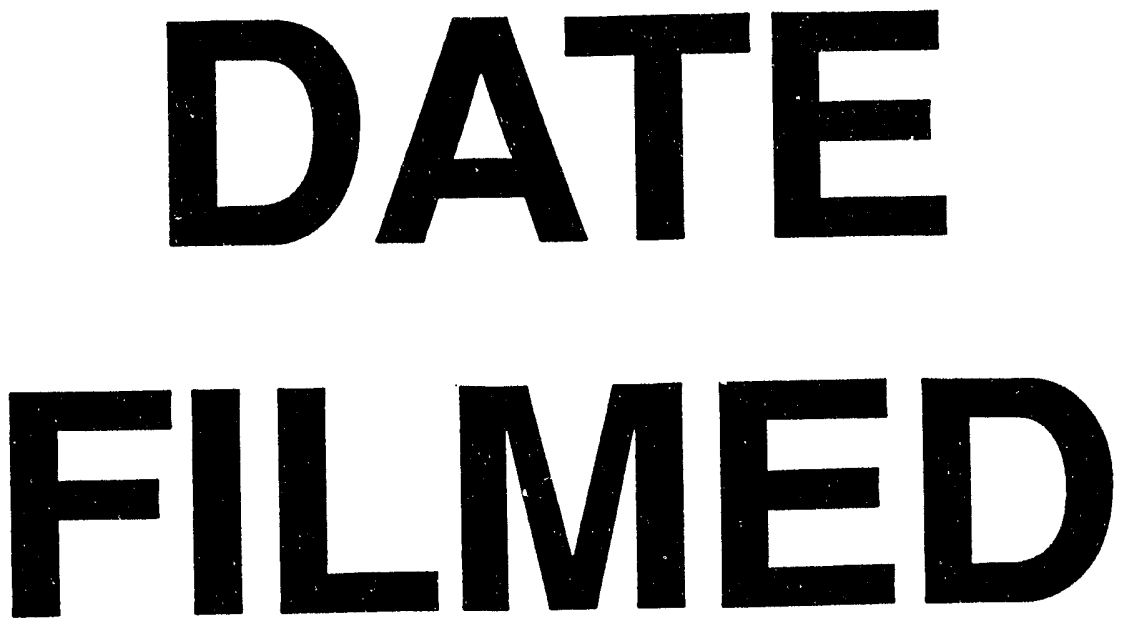

$8 / 17 / 94$
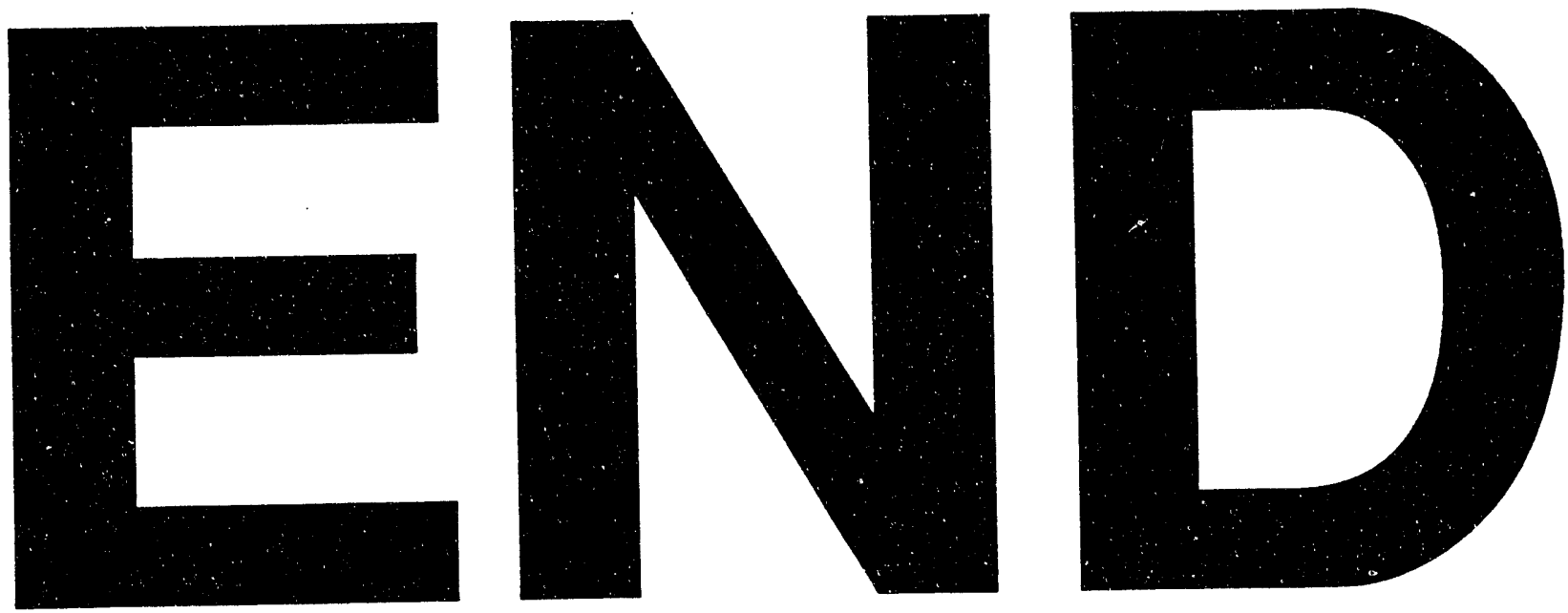


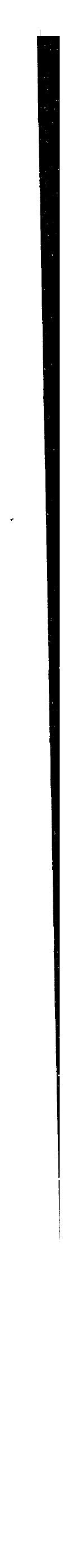

